\title{
İki Dillilik ve Görev Değiştirme Becerileri: Deneysel Desen Araştırmaların İhtiyacı
}

\author{
İlmiye Seçer ${ }^{1}$ \\ Koç Üniversitesi
}

\begin{abstract}
Özet
Birçok araştırma iki dilliliğin geçiş görev becerilerini olumlu etkilediğini göstermektedir. Özellikle, iki dil arasındaki geçiş yapma miktarı ile geçiş görev becerilerinin birbirleriyle ilişkili olduğu bulunmuştur. Fakat tüm araştırmalar aynı kanıda olmamakla birlikte bazı araştırmalar gruplar arası farklılıkları iki dilden ziyade kontrol edilmeyen faktörlere, örneğin sosyoekonomik düzeye veya katılımcı sayısının yetersizliğine yormuştur. Günümüzde bu alandaki araştırmaların çoğunluğu yarı deneysel desen ve korelasyon yöntemini kullanmıştır. Fakat bu yöntemlerle daha gelişmiş merkezi yönetici işlemleri olan bireyler mi ikinci bir dil edinmektedir, yoksa bu bireyler ikinci bir dil öğrendiği için mi geçiş görev becerileri gelişmektedir belirlemek imkânsızdır. Bundan dolayı büyük çocuklar, genç ve ileri yaşlı yetişkin örneklemlerini içeren deneysel desen araştırmalarına ihtiyaç vardır. Bu desene göre tek dilli katılımcılar, geçiş görev becerilerinin ölçülmesinin ardından seçkisiz bir şekilde deney veya kontrol grubuna atanır ve sadece deney grubundaki bireyler ikinci bir dil öğrenir. Ardından her iki grubun geçiş görev becerileri tekrardan ölçülerek, dil edinmenin etkileri incelenir. Dolayısıyla bu yazının amacı iki dillilik ile geçiş görev becerilerine ait mevcut literatür bulgularını gözden geçirip gelecek araştırmalar için yöntemsel önerilerde bulunmaktır. Bu alandaki araştırmaların iyileşebilmesi için dikkat edilmesi gereken hususlar ise şöyledir: ön-test ve son-testin olması, gruplara rastgele atama yapılması, aktif kontrol gruplarının olması. Aynı zamanda katılımcıların iki dillilik ile geçiş görev becerileri arasındaki ilişkiyle ilgili herhangi bir bilgisinin olup olmadığının öğrenilmesi ve geçiş görevlerinde başarılı olabilmeleri için olan motivasyonlarının ölçülmesi önemlidir.
\end{abstract}

Anahtar kelimeler: İki dillilik, geçiş görev becerileri, dil eğitimi, deneysel desenler

\begin{abstract}
The extant literature illustrates the positive effect of bilingualism on task switching abilities. In particular, frequency of language switching and task switching abilities have been shown to be positively correlated. However, not all studies find a beneficial effect of bilingualism on cognition indicating that rather than bilingualism per se other factors such as uncontrolled confounding factors such as socio-economic status and small sample sizes drive any group differences. To date, the majority of the research conducted in this area have employed quasi-experimental designs and correlational methods, which do not determine the effect of bilingualism on cognition. That is, it is unclear whether bilinguals have improved cognition because they speak two languages or whether people with better cognition become bilingual. For such reasons, there is a need for experimental designs that examine bilingualism and task switching abilities in older children, younger adults and older adults. This design entails a pre-test of task switching abilities of monolingual individuals in which thereafter they are randomly allocated to an experimental and control group. Only participants in the experimental group continue to learn a second language and then all participants are tested for their task switching abilities once again. The aim of the current paper is to provide an overview of the current literature related to bilingualism and task switching and suggest methodological future directions. Methodological improvements for future studies include the use of a pre and posttest design, random allocation of participants to groups, inclusion of active control groups, and the assessment of participants' prior knowledge of the relation between bilingualism and task switching abilities and their level of motivation to do well on switching tasks.
\end{abstract}

Keywords: Bilingualism, task switching abilities, language training, experimental designs

Yazışma Adresi: 'Öğr. Gör. İlmiye Seçer, Koç Üniversitesi, İnsani Bilimler ve Edebiyat Fakültesi, Psikoloji Bölümü, Rumelifeneri Yolu 34450 Sarıer / İstanbul, secer.ilmiye@gmail.com, ORC-ID: 0000-0002-0119-0075

Gönderim Tarihi: 25.05 .2020

Kabul Tarihi: 09.02.2021 
İki dillilik, insanların ana dilinden başka bir dili edinmesi (Diebold, 1961) ve ikinci dilini günlük hayatta iletişim için kullanması (Grosjean ve Miller, 1994) olarak tanımlanır. İki dilliliği ilk tanımlayanlar, bir bireyin iki dilli olabilmesi için ikinci dilindeki yetkinliğin ana dil seviyesinde olması gerektirdiğini belirtmiş olsalar da (Bloomfield, 1933, aktaran Diebold, 1961), güncel bakış açıları ikinci dilde farklı yeterlilik seviyeleri olan bireylerin de iki dilli olabileceğini vurgulamaktadır (MacKey, 2001). İki dilliliği oluşturan birçok bileşen vardır. Bunlara örnek olarak yeterlilik seviyesi (yazılı, konuşma, okuma ve dinleme), ikinci dilin kullanıldığı sıklık, süre ve bağlam (ev, iş yeri, okul vs.), iki dil arasında ne sıklıkla geçiş yapıldığ 1 ve bir dilde konuşurken diğer dildeki kelimelerin ne kadar az karıştırıcı olduğu verilebilir (MacKey, 2001).

Bir dili önce öğrenip sonraki zamanlarda başka bir dil daha edinen bireylere ardışık iki dilli denilmektedir (McLaughlin,1984, aktaran Liddicoat, 1991). İkinci dilin edinildiği yaş, ardışık iki dilli bireylerin erken veya geç iki dilli olarak kategorize edilebilmesini sağlamaktadır. İkinci dilini altı yasından önce edinenler ardışık erken iki dilli, altı yasından sonra edinilenler ise ardışık geç iki dilliler olarak sınıflandırılmaktadır (Tao ve ark., 2015). Ayrıca her iki dilde eşit yetkinliği olanlara dengeli iki dilli, bir dilinde diğerinden daha fazla yetkinliği olanlara ise dengeli olmayan iki dilli birey denilmektedir. Doğumdan hemen sonra, iki dile maruz kalıp, iki dili aynı anda (ilk üç yıl içerisinde) öğrenen çocuklar ise eş zamanlı iki dilli olarak adlandırılmaktadır (McLaughlin,1984, aktaran Liddicoat, 1991). Bu durumda, ilk ve ikinci dilin olmadığı, her iki dilin ilk dil olduğundan bahsedilmektedir.

Günümüzde, iki dillilik dil edinme, dil gelişimi, biliş ve nöropsikoloji gibi birçok alanda çalışılmaktadır. Birden fazla dil edinildiğinde beynin hangi bölgelerinin aktif olduğu, ikinci dilin hangi koşullarda daha kolay öğrenilebileceği ve bilişsel getirilerinin olup olmadiğ 1 araştırılmaktadır. Son yıllarda, iki dilliliğin bilişsel getirisinin olup olmadığı ve ileri yaşlı bireylerde bunama (demans) gibi bilişsel patolojiden koruyup korumadığ 1 (Bialystok ve ark., 2007; Craik ve ark., 2010) popüler bir araştırma konusu haline gelmiştir. Bilişsel becerilerin nasıl gelişebileceğinin araştırılması oldukça önemledir, zira bu becerilerin yemek yiyebilmek (Tuncay ve Fertelli, 2018), kendi ilaçlarını alabilmek veya para idaresi gibi günlük yaşamla ilişkili davranışların yerine getirilmesinde önemli rol oynadığı görülmektedir (Bell-McGinty ve ark., 2002; Cahn-Weiner ve ark., 2007).

Spor, müzik ve bilgisayar oyunları gibi bilişsel ve fiziksel egzersizlerin bireylerin bilişsel potansiyelini artırdığ 1 (Green ve Bavelier, 2008; Willis ve Schaie, 2009) ve bilişsel becerilerin gelişmesinde önemli etken olduğu araştırmalarca vurgulanmıştır. Bu bağlamda, iki dilliliğin de bilişsel becerilerin geliştirilmesinde etkili bir bilişsel egzersiz olduğu düşünülmektedir (Bialystok, 2011). Özellikle, merkezi yönetici işlevlerini; baskın olan davranışları engelleme / ket vurma (inhibition), görevler arası geçiş yapma (shifting) ve çalışma belleğindeki bilgileri güncelleme (updating) (Miyake ve ark., 2000) gibi işlevleri geliştirdiği düşünülmektedir. Bunun nedeni ise, iki dilli bireylerin her iki dilini de etkili bir biçimde koordine etmeleridir; bu koordinasyon konuşulmak istenilen dilin seçilmesini, karıştırıcı etki yaratmaması için otomatik aktif olan diğer dilin engellenmesini ve gerektiği zamanlarda diller arası geçiş yapılmasını içerir. Bu koordinasyon sayesinde edinilen pratik ile yönetici işlemler geliştirilebilmektedir.

Bilişsel avantaj kuramı, korelasyon ve nöro-görüntüleme ile önemli bir oranda desteklenmiştir (Abutalebi ve ark., 2014; Bialystok ve ark., 2006; Bialystok ve Viswanathan, 2009; Schroeder ve Marian, 2012; Schweizer ve ark., 2012). İki dilli bireylerin tek dilli bireylere göre merkezi yönetici işlemleri içeren; ket vurma, geçiş yapma ve güncelleme becerileri gerektiren birçok bilişsel görevde daha yüksek performans gösterdiği bulunmuştur (Antoniou, 2019). Öte yandan bazı araştırmalar hiçbir bilişsel avantaj bulamamış olup (Brito ve ark., 2016; Kaushanskaya ve ark., 2011; Luo ve ark., 2013; Papageorgiou ve ark., 2018), bu tür avantajlardan bahsedilmesinin yayın yanlılığından, diğer bir deyişle anlamlı fark olan bulguların anlamlı olmayanlara göre daha fazla yayınlanmasından (de Bruin ve ark., 2014) veya kat1lımcı sayısının yetersizliğinden oluşan güçsüz araştırma deseninden kaynaklandığını ifade etmişlerdir (Paap ve ark., 2015; 2016). Bununla birlikte sosyoekonomik düzey, etnik köken, gruplar arasında dilsel beceriler gibi karıştırıcı etki yaratacak faktörlerin yeterince kontrol edilmemesine de vurgu yapılmaktadır (Gathercole ve ark., 2016; Morton ve Harper, 2007; Paap ve Greenberg, 2013). Yaş, eğitim, sosyoekonomik düzey, cinsiyet ve el tercihi kontrol edildiği zaman iki dillilik ile ket vurma arasında olumlu bir ilişkinin olmadığı gösterilmiştir (Nichols ve ark., 2020). Ayrıca, genç yetişkinlerin bilişsel becerilerinin zirvede olmasından dolayı (Vinerte ve Sabourin, 2015), özellikle de bilişsel görevler kolay ise (Ibrahim ve ark., 2013; Qu ve ark., 2015), iki dilliliğin getirdiği bilişsel avantajların maskelenmiş olabileceği vurgulanmaktadır.

Genel olarak, iki dilliliğin biliş üzerinde olumlu etkilerinin yanı sıra hiçbir etkisinin olmadığı da görülmektedir ve bu nedenle iki dilliliğin bilişsel avantajlarının varlığı güncel bir tartışma konusudur. İki dillilikten gelişebilecek bir becerinin geçiş yapma becerisi olduğu düşünülmektedir, zira bu beceri, iki dilin koordinasyonunu gerektiren işlevler ket vurma, denetleme ve geçiş 
yapma, geçiş yapma becerileri (task switching abilities) ile örtüşmektedir (Abutalebi ve Green, 2008; Costa ve ark., 2009). Bu doğrultuda, iki dillilik ile geçiş görev becerileri yaygın olarak incelenmiştir (örneğin, Christoffels ve ark., 2015; Hernández ve ark., 2013; Jaekel ve ark., 2018; Marzecova ve ark., 2013; Paap ve Greenberg, 2013; Paap ve ark., 2017; Paap ve Sawi, 2014; Prior ve Gollan, 2011; Woumans ve ark., 2019; Zunini ve ark., 2019) ancak yöntemsel sınırlılıkların karmaşık bulgulara neden olduğu görülmektedir. İki dilliliğin bilişsel becerileri geliştirebilme ve demans tanısını geciktirebilme ihtimali bu konuda daha fazla çalışma gerektirdiğini düşündürmektedir. Dolayısıyla, mevcut yazının amacı çocukluk veya yetişkinlik döneminde ikinci bir dil edinmiş bireylerin geçiş görev becerilerini inceleyen çalışmaları gözden geçirip, çalışmalar arasındaki sınırlılıklar ile farklılıkları belirleyip, gelecek çalışmalara yöntemsel önerilerde bulunmaktır. Bir sonraki bölüm, geçiş görev becerilerini ayrıntılı şekilde inceleyecektir.

\section{Geçiș Görev Becerileri ve Ölçülmesi}

Bir görevin yerine getirilmesinde görev setinin etkinleşmesi, diğer bir deyişle görev uyaranı ile görev tepkisinin eşleştirilmesi gerekmektedir (Kiesel ve ark., 2010). Geçiş görev becerileri, birçok seçenek arasından yapılması planlanan göreve uygun kurallar ile tepkilerin seçilmesini ve seçilen kurallar bütününün görev tamamlanana kadar bellekte güncel tutulmasını, diğer göreve geçiş gerektiğinde ise bir önceki görev setinin bellekten silinmesini ve yeni görev setinin etkinleştirilmesini içerir (Abutalebi ve Green, 2008; Monsell, 2003; Rubin ve Meiran, 2005). Dolayısıyla geçiş görev becerileri; geçiş yapma, güncellenme ve ket vurma (engellenme) işlemlerinin başarıyla yapılmasını gerektirir (Abutalebi ve Green, 2008). Geçiş görev becerileri, bireylerin algısal uyaranlara tepki vermesine yönelik geçiş olmayan denemelerde aynı kurallar (tekrarlama deneme) ile ve kurallar arası geçiş gerektiren (karma görev blok) aşamalar içeren denemeler ile ölçülür (Monsell, 2003). Bu sayede iki tür görev bedeli (task cost) hesaplanır: geçiş (switching) ve karıştırma (mixing). Görev bedeli arttıkça görev performansında azalma, diğer bir deyişle tepki süresinde artış ve hata oranlarında yükselme olduğu görülür $(\mathrm{Ru}-$ bin ve Meiran, 2005).

Geçiş görev bedelleri (task switch cost) görevler arası geçiş yapma zorluğunun; diğer bir deyişle görev hedeflerinin yeniden etkinleştirilmesi, uyaran ve tepkilerin yeniden yapılandırılması ve ket vurma becerilerinin göstergesidir. Geçiş bedelleri, görevler arası geçiş yapabilme becerisini yansıtır ve karma görev bloklarında geçiş olmayan denemelerdeki tepki sürelerinin geçiş olan denemelerin tepki sürelerinden çıkartılmasıyla hesaplanır (Rubin ve Meiran, 2005). Diğer yandan karıştırma bedelleri, denetleyici işlemlerin yanında birçok diğer görevi yerine getirebilmeyi yansitır ve karma görev bloklarındaki geçiş olmayan denemelerdeki tepki süresi ile tekrarlama denemelerdeki tepki süresi arasındaki fark1 gösterir (Rubin ve Meiran, 2005).

Yaygın kullanılan geçiş görev paradigmalarından biri haline gelen renk-şekil geçiş görevinde, katılımcılardan kırmızı ve yeşil olan renklere veya daire ve dikdörtgen olan şekillere önceden belirlenmiş tuşlara basarak tepki vermeleri istenmektedir (Prior ve MacWhinney, 2011). Hangi uyaranlara (renk veya şekil) tepki verilmesi gerektiğini bir renk gradyenti veya küçük siyah oklardan oluşan ipuçları belirlemektedir (Prior ve MacWhinney, 2011). Bu görevde tekrarlama denemelerinde bireyler sadece renklere veya sadece şekillere tepki vermekte, karma görev bloklarında ise renk ve șekil görevlerine bazen geçişim yaparak tepki veriliyor. Bu görev sayesinde, geçiş ve karıştırma bedelleri hesaplanarak, geçiş görev becerilerin seviyesi belirlenmektedir.

Geçiş görev becerileri iki uyaran arasında geçiş yapılmasını gerektirmekte olup, iki dilli bireyler de aynı şekilde iki dilleri arasında geçiș yapabilmektedir. Örtüşen davranışlar doğrultusunda, bilişsel becerilerin iyileşmesi beklenmektedir ve bir sonraki bölümde ayrıntılı şekilde incelenecektir.

\section{İki Dillilik, Diller Arası Geçiş Yapma ve Geçiş Görev Becerileri}

Dil modu (language mode), iki dilli bireylerin herhangi bir anda dillerinin etkinleşmesi durumunu açıklayan kavramdır (Grosjean, 2013; Grosjean ve Miller, 1994). Dil modu çerçevesinde, tek dil modundan iki dil moduna uzanan evrede diller farklı derecelerde etkinleşir. İletişime (sözlü ve/veya yazılı) geçilen kişi tek bir dil biliyor ise iki dilli birey tek dil modundadır ve ikinci dil devre dışı bırakılır, diğer bir deyişle aktifleşmez. Ancak karşıdaki kişi her iki dili de biliyor ise, iki dilli birey iki dil modundadır. Burada, iletişim için seçilen dil (esas dil) en çok etkinleşen dilken, diğer dil farklı derecelerde aktif olabilir. İki dil modunda bireyler iki dilini karışt1rarak veya bir dilden diğerine geçiş yaparak konuşabilmektedirler.

İki dil arasında geçiş yaparak konuşmak, düzenek değiştirme (code-switching) olarak da bilinir (Grosjean ve Miller, 1994). Düzenek değiştirme, iki dil kurumu (seti) arasında geçiş yapabilme, gereksiz olan dilsel uyaran-tepki setlerini engelleyebilme ve odağın bir önceki dilden alınıp yeni dile verilebilmesi gibi bilişsel kontrol işlemlerini içerir (Abutalebi ve Green, 2008; Blanco-Elorrietaa ve ark., 2018). Bilişsel kontrol işlemlerinin düzenek değiştirme ile nasıl gelişebileceğini açıklayan kuramlardan biri, uyarlanabilir kontrol hipotezidir (adaptive control hypothesis) (Green ve Abutalebi, 2013). Bu 
hipotez, iki dilli bireyin dillerini kullandığ koşulu olduğunu ifade etmektedir: tek dil bağlamı (single language context), çift dil bağlamı (dual language context) ve yoğun düzenek değiştirme bağlamı (dense code-switching context). Bireyin içinde bulunduğu bağlam; hedef sürdürme (goal maintenance), çatışma kontrollü (interference kontrol): çatışma denetleme (conflict monitoring) ve çatışma bastırma (interference suppression), belirgin işaret algılama (salient cue detection), seçici tepki ketleme (selective response inhibition), göreve odaklanma (task engagement), görevden odağın alınmas1 (task disengagement) ve firsatçı planlama (opportunistic planning) bilişsel kontrol becerilerinden hangilerinin etkinleşebildiğini ve buna bağlı olarak gelişebildiğini belirlemektedir (Green ve Abutalebi, 2013).

Tek dil bağlamda, iki dilli bireyler tek bir dil kullanır, dolayısıyla diller arası geçiş yapılmamaktadır. Konuşulan dilde kesinti olmaması için hedef sürdürme becerisine ihtiyaç duyulur ve iki dilin birbirine karışmaması için kullanılmayan dile ket vurulması gerekir. Çift dil bağlamında bireyler her iki dilini de ev veya iş gibi aynı ortamlarda ancak farklı zamanlarda veya farklı kişilerle kullanır dolayısıyla dil setleri rekabet içindedir (tek dil bağlamında olduğu gibi). Bu durumda firsatçı planlama becerisi hariç tüm bilişsel kontrol becerileri etkinleşmektedir. Diğer yandan yoğun düzenek değiştirme bağlamında bireyler tümce içerisinde her iki dilde serbest bir şekilde geçiş yapabilmektedirler. Dil setleri birbiri ile rekabet içerisinde olmadığından, yoğun düzenek değiştirme bağlamında herhangi bir dilin engellenmesi gerekmemektedir dolayısıyla sadece planlama becerisi etkinleşmektedir. Buradan bilişsel becerilerin gelişmesini en çok çift dil bağlamının sağlamakta olduğu anlaşılmaktadır. Bu hipotez 1şı̆̆ında, çift dil bağlamında bulunan iki dilli bireylerin görev değiştirme (ket vurma ve dikkatin bir görevden alınıp diğerine verilmesini) becerilerinin daha fazla gelişebileceği ön görülmektedir. Düzenek değiştirme bağlamları incelendiği zamanlarda, çift dil bağlamının tek dil bağlamına göre geçiş ve karıştırma bedellerini (Khodos ve Moskovsky, 2020) veya sadece geçiş bedellerini (Hartanto ve Yang, 2016) olumlu etkilediği bulunmuştur.

Nöro-görüntüleme araştırmalarının bulguları ile yapılan meta-analiz çalışmaları sonucunda bilişsel kontrol işlemlerinin dil geçiş becerileri ile örtüşen birçok beyin bölgesi (sol inferior frontal girus, sol orta temporal girus, sol orta frontal girus, sağ presentral girus, sağ üst temporal girus, on-tamamlayıcı motor alanı ve bilateral kaudat nukleus) ile ilişkili olduğu vurgulanmıştır (Luk ve ark., 2012). Blanco-Elorrietaa ve arkadaşları (2018), diller arasında geçiş sırasında odağın bir önceki görevden alınması arka-yan prefrontal (dikkat değișimi sağlayan ve engelleme işlemleri sağlayan bölge) ve ön singulat kortex'i (hata denetleme ve tespiti işlemlerini sürdüren bölge) etkinleştirirken, odağın yeni göreve verilmesinin bu beyin bölgelerini etkilemediğini bulmuştur. Bu bulgular, bir önceki dilin engellenebilmesinin dil geçiş becerileri için olan önemini göstermektedir.

Bilişsel kontrol, geçiş görev ve dil geçiş mekanizmalarının beyindeki sol inferior frontal girus ile kaudat nukleus (Hosoda ve ark., 2012), precuneus, posterior singulum, fuziform girus ve on-tamamlayıc1 motor alanı (de Baene ve ark., 2015), insular ve bazal gangliya (Weissberger ve ark., 2015) örtüştüğü düşünülür ise, iki dil arasında geçiş yapan bireylerin geçiş görev becerilerini etkinleştirdiğinden daha gelişmiş olması beklenmektedir (Paap ve ark., 2017). Bu hipotezi araştıran birçok çalışma olup bir sonraki bölümde detaylı bir şekilde açıklanacaktır.

\section{Korelasyon Araștırmaları}

Korelasyon araştırmaları, iki dilliliğin geçiş görev becerileri konusunda avantaj sağlayıp sağlamadığı konusunda farklı bulgular ortaya koymaktadır. Birçok farklı geçiş görev paradigmas1-örneğin renk-şekil geçiş görevi kullanılarak yapılan bazı araştırmalar, tek dilli muadillerine kıyasla iki dilli genç yetişkinlerde (Christoffels ve ark., 2015; Marzecova ve ark., 2013; Prior ve Gollan, 2011; Prior ve Macwhinney, 2010; Tao ve ark., 2015; Woumans ve ark., 2019; Yang ve ark., 2018; Zunini ve ark., 2019) ve orta ve yaşlı bireylerde (Houtzager ve ark., 2015; Zunini ve ark., 2019) daha az geçiş bedeli bulurken, diğer araştırmalar iki dilli çocuklarda (Barac ve Bialystok, 2012, Bialystok, 2010), genç yetişkinlerde (Wiseheart ve ark., 2014) ve yaşlı bireylerde (Zunini ve ark., 2019) azalan karıştırma bedeli bulmuşlardır. Bu bulgular, geçiş görev becerilerinin iki dillilik sayesinde daha iyi hale gelmiş olduğunun göstergesi olarak kabul edilmiştir. Bu olgu, iki dilli bireylerin dil geçiş tekrarı ile edindiği zihinsel set geçiş becerisi ile açıklanabilir.

$\mathrm{Bu}$ bağlamda, bazı araştırmalar iki dilli bireylerin iki dilleri arasındaki geçiş miktarı arttıkça geçiş görev becerilerinde iyileşmeye yol açtığını göstermektedir (Barbu ve ark., 2018; Hartanto ve Yang, 2016; Soveri ve ark., 2011; Xie, 2014; Yim ve Bialystok, 2012). Örneğin, Çince-İngilizce konuşan iki dilli bireylerin ikinci dilini daha fazla kullanması, renk-şekil geçiş görevinde daha az geçiş bedellerine yol açarken, iki dil arasında geçiş sıklığ1 arttıkça karıştırma bedellerinde azalma olduğu bulunmuştur (Xie, 2014). Bu bulgular, sadece ikinci bir dil bilmenin yeterli olmadığını, geçiş görev becerilerin gelişiminde diller arası geçiş yapma sıklığının da önemli bir rol oynadığını göstermektedir. Buna ek olarak iki dilliliğin biliş üzerindeki etkilerini incelerken iki dilliliğin kategorik bir değişkenden ziyade sürekli bir değișken olarak ölçülmesinin gerekliliği vurgulanmıştır. 
$\mathrm{Bu}$ bulguların yanında, birçok araştırma ise (Chung-Fat-Lim ve ark., 2018; Hernández ve ark., 2013; Jaekel ve ark., 2018; Mor ve ark., 2014; Moradzadeh ve ark., 2014; Paap ve Greenberg, 2013; Paap ve ark., 2017; Paap ve Sawi, 2014; Rodriguez-Pujada ve ark., 2013; Shulley ve Shake, 2016; Sörman ve ark., 2019; Timmermeister ve ark., 2020; von Bastian ve ark., 2015) dil edinme/geçiş ile geçiş görev becerileri arasında bir bağlantı bulamamıştır. Örneğin, Paap ve arkadaşları (2017) içlerinde 122'sinin karma diller konuştuğu iki dilli toplam 236 genç yetişkinin geçiş bedelleri arasında anlamlı bir fark olmadığını bulmuştur. Bunun yanında, diller arasındaki geçiş yapma sıklığının geçiş görev becerileri üzerinde bir etkisinin de olmadığını göstermiştir. $\mathrm{Bu}$ araştırmada çok sayıda katılımcıdan veri toplanılmış olmasına rağmen, dillerin karma olmasından dolayı ortaya çıkabilecek diller arası fonolojik ve yazılım benzerliklerini veya farklılıklarını kontrol etmemiştir. Dillerin benzerliği ve farklılığının bilişsel avantajları etkileyebilecek önemli bir faktör olduğu düşünülmesine rağmen (Oschwald ve ark., 2018), etkisi ile ilgili kesin bir yargiya varmak mümkün değildir (Sörman ve ark., 2019). Shulley ve Shake (2016) karma diller konuşan iki dilli ve tek dilli bireyler arasında anlamlı bir fark bulamayıp, bunun sebebinin dillerin benzerliğinden veya farklılığından kaynaklanmadığını vurgulamıştır. Gerçekten de bir fark var ise, ikinci dilin öğrenildiği bağlamın veya kullanıldığ1 sıklığın etkili olabileceğini öne sürmüştür.

Bu aşamada katılımcı sayısının yeterliliği, karıştırıcı faktörlerin (sosyoekonomik düzeyi, kelime hazinesi, zekâ) gruplar arasında sabit tutulması, tek dilli bireylerin sadece bir dil bilmesi, iki dilli bireylerin konuştuğu dillerin benzerliği, ikinci dilin edinildiği yaş, ikinci dilde akıcılık ve yetkinlik, düzenek değiştirme bağlamları, ikinci dilinin kullanıldığı sıklık ve öğrenildiği bağlamokul veya ev- gibi birbirine zit bulgulara sebep olabilecek birçok faktör gelecek araştırmalar tarafından dikkate alınmalıdır. Bunun dışındaki olası yöntemsel iyileştirmeler, diller arası geçiş gibi geçiş görev becerilerini geliştirebilecek faktörlerin laboratuvar ortamında manipüle edilerek incelenmesidir. Bu yöndeki araştırmalarda son y1llarda artış gözlemlenmektedir ve bir sonraki bölümde ayrıntılı inceleneceklerdir.

\section{Dil Geçiş Egzersizleri}

Merkezi yönetici işlemlerinin ikinci bir dil edinilmesini etkilediğinden (Kapa ve Colombo, 2014), araştırmalarda etki yönünün belirsizliğinin sebeplerinden biri, tek dilli bireylerle karşılaştırılan iki dilli bireylerin ikinci dillerini önceden öğrenmeleri olabilir. Bu bulgular, geçiş görev becerilerinin doğası ile ilgili soruları da beraberinde getirmektedir: Dil geçiş pratiği mi geçiş görev becerilerini iyileştirmektedir, yoksa bu becerileri geliş- miş bireyler mi ikinci dil edinmektedir? Bu belirsizlik mevcut bilişsel avantaj bulgularına gölge düşürmektedir. Bunun yanında, korelasyon araştırmaları, iyileşmiş geçiş görev becerilerini dil geçiş yapma miktarlarına yorarken, bu çalışmalarda dil geçiş oranları direkt olarak manipüle edilmemiştir.

Bu doğrultuda, birkaç araştırma dil geçiş egzersizlerinin (Dong ve Liu, 2016; Kang ve ark., 2017; Liu ve ark., 2019; Prior ve Gollan, 2013; Timmer ve ark., 2018; Wu ve ark., 2018) geçiş görev becerileri üzerindeki etkilerini incelemiştir. Bu çerçeve doğrultusunda, Prior ve Gollan (2013) dilsel olan ve olmayan geçiş egzersizlerinin geçiş görev becerilerini nasıl etkilediği üzerine çalışmalar yapmıştır. Bu deney üç dil grubunu birbirleriyle kıyaslayarak gerçekleşmiştir: (a) erken İspanyol-İngilizce (ortalama yaş $=20,3$ y1l) ve Mandarin-İngilizce konuşan iki dilli genç bireyleri (ortalama yaş $=20$ y1l), (b) geç İbranice-İngilizce konuşan iki dilli genç bireylerde (ortalama yaş $=25$ yıl) ve (c) sadece İngilizce konuşan tek dilli genç bireyler (ortalama yaş $=20,1$ yıl). Geçiş görev becerilerini ölçmek amacıyla katılımcıların geçiş olmayan bloklardaki denemeler ile geçiş içeren bloklardaki denemelerde algisal bir uyarana tepki vermeleri istenmiş, geçiş ve karıştırma bedelleri hesaplanmıştır. Bu deneyin bulguları, egzersizlerin ilk günü ile ikinci günü kıyaslandığında, egzersizlerin tek dilli ve iki dilli bireylerin tüm denemelerdeki genel tepki hızlarını etkilediğini ortaya koymuştur, fakat bu etki bir hafta sonrasında muhafaza edilememiştir. Bunun yanında dil egzersiz gruplar arası geçiş ve karıştırma bedelleri üzerinde hiçbir etkisi olmamıştır. Sonuç olarak yetersiz egzersiz mevcut bulgulara yol açabileceği vurgulanmıştır.

Benzer bir şekilde, Kang ve arkadaşları (2013) dil geçiş egzersizlerinin geçiş görev becerilerini nasıl etkilediğini incelemiştir. $\mathrm{Bu}$ araştırmada, dengeli olmayan Çince-İngilizce konuşan $(n=16)$ geç iki dilli genç yetişkin katılımcılar (ortalama yaş $=22$ yıl), ipucu içeren resim adlandırma görevini tamamlamıştır. Bu görevde, birtakım siyah beyaz çizimlerin her iki dilde adland1rılması istenmişti. Hangi dilde adlandırma yapılacağını resmin çerçevesi olan renk belirlemiştir. Ön-test, sekiz gün süren ve günde üç kere dörder bloktan oluşan (her blokta 41 deneme olan) egzersiz ve son-testten oluşan bir deneydir. Ön test ile egzersiz kıyaslandığında, resimlerin adlandırılma sürelerinin egzersiz sonrası daha kısa, geçiş bedellerinin de daha az olduğu görülmüştür. Bu bulgular dil geçiş egzersizlerinin etkili olduğunun göstergesidir.

Dong ve Liu (2016) gerçek hayatta rastlanılabilecek bir dil geçiş egzersizi uygulamıştır. Üç gruptan oluşan, akademik dönem içerisinde yorumlama (okuduğu anlama), çevirmenlik ve İngilizce derslerinden birinde öğrenci olan; dengeli olmayan Çince-İngilizce konuşan $(n=145)$ iki dilli genç yetişkinlerin (ortalama yaş $=$ 
19,69 y1l) geçiş görev becerileri ölçülmüştür. Dönemin başında ve sonunda katılımcılar renk-şekil geçiş görevini tamamlamıştır. Yorumlama dersi alan iki dilli bireylerin çevirmenlik ve İngilizce dersi alan bireylere göre son-testte daha az geçiş bedellinin olduğu bulunmuştur. Çevirmenlik ve İngilizce dersi alan öğrencilerin geçiş bedelleri arasında ise anlamlı bir fark olmadığı görülmüştür. Bu bulgular, dil geçiş egzersizleri sonrası oluşabilecek bilişsel avantajların, egzersizlerin getirdiği bilişsel yük ile ilişkili olabileceğini ortaya koymuştur. Bu tür araştırmalar, laboratuvar ortamındaki dil geçiş süreçleri ile gerçek hayattaki dil geçiş süreçleri arasında merkezi yönetici işlemler ile etkinleşen beyin bölgeleri açısından farklılık olduğunu gösterdiğinden literatür için oldukça önemlidirler (Blanco-Elorrietaa ve ark., 2017).

Diğer yandan, Wu ve arkadaşları (2018) gerçekleşen dil geçiş egzersizlerinin geçiş bedellerini nasıl etkilediğini ipuçlu resim adlandırma görevi kullanarak ölçmüştür. Bu araştırmada, dengeli olmayan Çince-İngilizce konuşan geç iki dilli genç bireyler (deney $1 n=36$ ortalama yaş $=22,51$ y1l, deney $2 n=35$ ortalama yaş = 22,11 yıl) çizim adlandırmıştır. Birinci çalışmada renk ve adlandırmanın yapılacağı dil tüm aşamalar boyunca sabitken, ikinci çalışmada değiştirilmiştir. Bu adlandırma egzersizi günde iki seans olmak üzere toplamda dört seans da tamamlanmış, her seans sekiz bloktan oluşan 41 deneme (her seans 328 deneme) içermiștir. Ana dilde, yani Çincede olan geçiş bedellerinde egzersiz ile azalma olurken, ikinci dilde, yani İngilizcede olan geçiş bedellerinde aşamalar arası fark bulunmamıştır (1. Deney). İkinci deneyin bulguları ise egzersizin bir etkisinin olmadığını ve her iki dildeki geçiş bedellerinde azalma olmadığını göstermektedir. Wu ve arkadaşları (2018), ikinci deneydeki işleme taleplerinin artmasının, birinci deneyde egzersizin getirdiği etkiyi örtmüş olabileceğini söylemiştir. Adlandırmanın hangi dilde olacağının belirsizliği, hazırlanma etkisini etkilemiş ve yeterince hazırlanamamanın geçiş görev becerisini olumsuz etkilemiş olma ihtimali de mevcuttur, bu nedenle bu bulguların üzerinde daha büyük bir önemle durulması gerekmektedir.

Şimdiye kadar mercek altına alınmıș olan ve egzersiz içeren araştırmaların kontrol grubu bulunmamaktaydı. Bu eksiklikler ışı̆̆ında, Trimmer ve arkadaşları (2018), dil geçiş içeren ve içermeyen iki tür egzersizin geçiş görev becerilerinin üzerindeki etkisini araştırmıştır. Bu deneyde Katalanca ve İspanyolca konuşan iki dilli genç bireyler (ortalama yaş $=22 \mathrm{y} 1$ ), dil geçiş egzersiz grubuna $(n=30)$ veya dil geçiş olmayan egzersiz grubuna $(n=30)$ seçkisiz atanmıştır. Dil geçiş egzersizleri diğer araştırmalarda olduğu gibi bir blok içerisinde her iki dilde resimlerin adlandırılmasını içerirken, diller aras1 geçiş olmayan egzersiz grubunda ise her blokta resimler sadece tek bir dilde adlandırılmıştır. Egzersiz öncesi ve sonrası dilsel olan (resim adlandırma) ve olmayan (renk-şekil ayırt etme) geçiş görevleri ile geçiş ve karıştırıcı bedelleri ölçülmüştür. Bulgular, ön-testle kıyaslandığında son-testte dilsel olan ve olmayan geçiş görevinde sadece geçiş bedellerinde azalma olduğunu göstermiştir. $\mathrm{Bu}$ bulgular, dilsel olan bir egzersizin dilsel olmayan görevlere de etkilerinin taşabileceğini gösteriyor.

Benzer bir şekilde, Liu ve arkadaşları (2019), dil geçiş egzersizlerinin dil geçiş becerisinin önemli iki işlemi olan denetleme ve ket vurma yetisini nasıl etkilediğini inceleme amacıyla 60 Çince-İngilizce konuşan geç iki dilli genç yetișkin (ortalama yaş $=22$ y1l) üzerinde çalışmalar yapmıştır (1. Deney). Birinci deneyde de katılımcılar dil geçiş egzersiz grubu $\left(n=27^{1}\right)$ ve kontrol grubu $(n=31)$ olarak iki gruba seçkisiz atanmış; ön-test, (deney grubu için) egzersiz ve son-test olarak üç aşamadan geçirilmişlerdir. Ön-test ve son-testte denetleme becerilerini ölçme amacıyla renk-şekil geçiş görevi kullanılmıştır. Dil geçiş egzersizlerinde bulunan ipucu içeren adlandırma görevinde katılımcılardan 0 ile 9 arasındaki rakamları Çince ve İngilizce adlandırmaları istenmiştir. Adlandırmanın hangi dilde yapılacağını ipucu görevi gören Çin veya Amerikan bayrağı belirlemekteydi. Bu egzersiz günde iki seanstan oluşan sekiz seans boyunca devam etmiştir. Ön-testle kıyaslandığında son-testteki karıştırma bedellerindeki azalmanın kontrol grubuna kıyasla deney grubunda daha fazla olduğu görülmüştür. Azalan karıştırma bedelleri, iyileşmiş denetleme becerisi olarak belirlenmiştir. Bu iyileşmenin iki dil arasındaki geçişten kaynaklanıp kaynaklanmadığını teyit etmek amaçlı ikinci bir deney gerçekleşmiştir. İkinci deneyde Çince-İngilizce konuşan 50 genç katılımcı iki egzersiz grubuna; iki dilde adlandırılma $(n=25)$ ve ikinci dilde adlandırma $(n=25)$ gruplarına atanmış ve yine ön-test, egzersiz ve son-test uygulanmıştır. Dil geçiş egzersizleri, birinci deneydeki gibi 0 ile 9 arasındaki rakamların her iki dilde adlandırılmasını içerirken, ikinci dilde egzersizi rakamların sadece İngilizce dilinde adlandırılmasını içermekteydi. İkinci deneyin bulguları, ön-test ile kıyaslandığında son-testteki karıştırma bedellerindeki azalmanın, dil geçiş egzersiz grubunda daha fazla olduğunu göstermiştir. Genel olarak 1. ve 2. deneydeki bulgular, dil geçiş egzersizlerinin denetleme becerilerini iyileşebileceğini göstermektedir.

Dil egzersiz yöntemi ile geçiş görev becerilerini incelemeleri, çalışmaların bazılarında kontrol grubunun

1 Bir katılımcı dil geçiş egzersizinde bulunmadığı için verileri kontrol grubuna dahil edilmiştir, iki katılımcın testti tamamlamasından dolayı verileri analizden çıkartılmıştır. 
(Trimmer ve ark., 2018) ve ön-testin (Liu ve ark., 2019) olması bu araştırmaların güçlü yönlerindendir². Bu çalışmalara ek olarak, iki dillilik ile geçiş görev becerileri boylamsal olarak çalışılmıştır. Bir sonraki bölümde bu çalışma ayrıntılı bir şekilde açıklanacaktır.

\section{Dil Eğitimi Araştırmaları}

İki dilli olmanın bilişsel avantaj getirip getirmediğini öğrenmek amacıyla boylamsal araştırmalara ihtiyaç duyulmaktadır. Bu açı̆̆ı kapatmak üzere, sınırlı sayıda araştırma (Ramos ve ark., 2017; Woumans ve ark., 2016) iki dilli olmanın biliş üzerindeki etkisini boylamsal olarak incelemiştir. Bu araştırmalardan sadece Ramos ve arkadaşları (2017) geçiş görev işlemlerini araştırmıştır. Ramos ve arkadaşları (2017), yaşlı bireylerin geçiş görev becerilerini dil eğitimi öncesinde ve sonrasında ölçmüştür. Bu deneyde, iki grup İspanyolca konuşan tek dilli yaşlı bireyler görev almıştır: dil eğitimi programına kayıtlı olan $(n=26)$ (ortalama yaş $=67,42$ yıl) ve dil eğitimi programına kayıtlı olmayan bireyler $(n=17)$ (ortalama yaş $=69,18$ yıl). Dil eğitimi 10 kişilik gruplar halinde haftada 330 dakika olup sekiz ay sürmüştür. Her iki grubun geçiş görev becerileri renk-şekil geçiş görevi kullanılarak dil eğitimini öncesinde ve sonrasında ölçülmüştür. Ön-teste göre deney grubunun geçiş bedelleri kontrol grubundakilerden farklı bulunmamıștır. Bu bulgular, dil eğitiminin yaşlı bireylerin geçiş görev becerilerinde bir iyileşme sağlamadığını göstermektedir. Ancak, dil eğitiminin kısa süreli (toplam sekiz ay) olması ve bireylerin sınıf dışında ikinci dili kullanmamaları, yeterince bir pratiğin edinilmemesine, geçiş görev becerilerinin gelişmemesine neden olmuş olabilir. Bu durumda bilişsel avantaj elde edebilmek için ikinci dilin en az ne kadar süre kullanılması gerektiği araştırılmalıdır.

\section{Tartışma}

Genel olarak, iki dillilik ile geçiş görev becerilerini araştıran çalışmalar arasında çelişkili sonuçları olanlar vardır. Bundan dolayı sinırlılıklar göz önünde bulundurulmakta, daha büyük örneklemler kullanılarak ve karıştırıcı faktörler sabit tutularak çokça tekrarlama araştırmaları yapılıyor. Ayrıca, bu çalışmalar dil olguları doğrultusunda bulguları yorumlamaktadır. Bazı çalışmalar bilişsel avantaj edinebilmek için ikinci dilde yeterlilik seviyesinin önemli olduğunu gösterirken (Tse ve Altarriba, 2015), diğerleri ikinci dilin kullanıldığı miktar ve diller arası geçişlerin önemine vurgu yapmaktadır (Xie, 2014). Hatta, diller arası geçişlerin gönüllü olup olmamasının da geçiş bedellerini etkilediği bulunmuştur (Jevtovic ve ark., 2019).
İki dillilik çalışılırken dil faktörlerinin göz önünde bulundurulması önemlidir. Bunun nedeni iki dillilik ile bilişsel beceriler arasında anlamlı ilişki bulunmadığ zamanlarda (Nichols ve ark., 2020) ikinci dilin yeterince kullanılmamasından veya diller arası yeterince geçiş yapılmamasından edinilen pratiğin yeterliliğinin tart1Şılabilir olmasıdır. Bu bakış açısı iki dil arasında sözel geçiş yapıldı̆̆ını varsaymakta olup çalışmalar genelde sözel geçişleri incelemektedir. Ancak yedi ile dokuz aylık, henüz konuşamayan ve iki dil ortamında büyüyen bebeklerin tek dil ortamında büyüyen bebeklere kıyasla odaklarını bir uyarıcıdan diğerine daha hızlı döndürebildikleri ve uyarıcılar arasında daha fazla geçiş yapabildikleri bulunmuştur (D’Souza ve ark., 2020; Kovacs ve Mehler, 2009). Bu bulgular, yönetici işlemlerin gelişebilmeleri için sözel dil koordinasyonun gerekmediğini, iki dile sadece işitsel maruz kalmanın bilişsel kazanç için yeterli olabileceğini göstermektedir. Bu bulgular 1şığında, iki dilliliğin bilişsel gelişime nasıl yol açtığını belirleyebilmek için farklı dil koordinasyonlarının da araştırılması gerekmektedir. Günümüzde yazılı iletişimlerde iki dildeki kelimeler karıştırılarak konuşulmakta ve bu tür geçişlerin araştırılması önerilmektedir.

Farklı yaştaki bireyler ile yapılan çalışmalar, iki dilliliğin avantajlarının gelişim süreçleri ile de ilişkili olabileceğini göstermektedir. Crone ve arkadaşları (2006) çocukların birden fazla görevi denetlemekte daha başarılı olduğunu, ancak iki görev seti arasında geçiş yapmakta ve bir önceki setten oluşan karıştırmanın üstesinden gelebilmekte (geçiş bedelleri olarak yansıyan) zorlandığını bulmuştur. Bu doğrultuda çocuklar ile yapılan çalışmalar, iki dilliliğin sadece denetleme becerilerini etkilediğini ve çocukların geçiş becerilerinin gelişim süreçlerini tamamlayana kadar iki dillilik tarafından etkilenmediğini göstermiştir (Park ve ark., 2018).

İki dilliliğin araştırılmasında kullanılan yöntemler de önemlidir. Mevcut çalışmalar, yarı deneysel desenler, korelasyon ve denekler arası yöntemlerle birlikte tek dilli ve iki dilli bireylerin kıyaslanmasını veya denekler içi kıyaslamanın yapıldığı; dil olguları doğrultusunda iki dilli bireylerin becerilerinin incelenmesini içeren desenler kullanmışlardır. Ancak iki dillilik ve biliş; öntest sonrasında tek dilli büyük çocuklar, genç yetişkinler ve ileri yaşlı yetişkinlerin deney ve kontrol gruplarına seçkisiz atanmalarının ardına sadece deney grubundaki bireylerin ikinci bir dil öğrenmelerini içeren deneysel bir desen ile araştırılmamıştır. Bir sonraki bölüm bu tür araştırmalara neden ihtiyaç duyulduğunu daha ayrıntılı inceleyecektir.

2 Kontrol gruplarının ve ön-testlerin önemi 'Gelecek Deneyler: Deneysel Desen Araştırmaları' bölümde ayrıntılı bir şekilde açıklanacaktır. 


\section{Gelecek Deneyler: Deneysel Desen Araştırmaları}

Genel olarak, dil egzersizlerinin etkilerini inceleyen araştırmaların çoğunluğu geçiş görev becerilerinin iyileştirilebileceğine işaret etmektedir. Fakat her araştırmada olduğu gibi bu araştırmalarda da sınırlılıklar mevcuttur. Ön-testlerin eksikliği (Prior ve Gollan, 2013), kontrol gruplarının olmayışı (Kang ve ark., 2013 Liu ve ark., 2019; Wu ve ark., 2018) ve katılımcıların deneysel ve kontrol gruplarına seçkisiz atanmamasının gibi sınırlılıklar gözden kaçırılmamalıdır (Ramos ve ark., 2017). $\mathrm{Bu}$ karmaşıklığa son verebilecek bir yöntem deneysel desenlerin kullanılmasıdır. Bu yöntem, birbirine denk bir grup tek dilli bireyin geçiş görev becerileri ölçüldükten sonra seçkisiz bir şekilde dil edinen ve dil edinmeyen iki gruba atanmasını ve dil eğitiminin bitiminin ardından her iki grubun tekrardan geçiş görev becerilerinin ölçülmesini içerir.

Araştırmalarda ön-testlerin olmaması önemli bir sınırlılıktır. Geçiş görev becerilerinin önceden hangi seviyede olduğunu bilmemek, sonrasında gruplar-arası farklılıkların ne kadarının eğitimden kaynaklı olduğunun belirsizleşmesine neden olmaktadır. Deney grubundaki bireylerin merkezi yönetici işlemlerinin eğitim öncesinde iyi olması ve görülen herhangi bir farkın aslında var olan bir farktan kaynaklanması olasıdır. Diğer yandan, ön-test olmadan anlamlı fark olmayan durumlarda, eğitimin etkisinin olmadığını söylemek de mümkün olmamaktadır. Bu durumda öncesine göre bir iyileşme olmas1, ancak eğitim süresinin yeterli olmaması olasıdır. Bu nedenle öncesi ve sonrası değişimin yönünü görebilmek faydalı olacaktır.

Bazı araştırmalar (Kang ve ark., 2013, Liu ve ark., 2019; Wu ve ark., 2018) geçiş görev becerilerini egzersiz öncesi ve sonrası ölçmesine rağmen, sadece iki dilli bireyleri test etmiştir. Bu durumda kontrol grubunun olmamas1 (tek dilli bireyler) bir sınırlılıktır. Kontrol grubunun olması, azalan geçiş veya karıştırma bedellerinin egzersizden kaynaklı olduğunu daha net ortaya koyabilmeyi sağlayacaktır. Aksi takdirde yapılan herhangi bir aktivitenin de bilişsel iyileşmeyi sağlaması söz konusudur. Bu sınırlılı̆̆ Liu ve arkadaşları (2019), dil geçiş içermeyen ikinci bir egzersiz grubu atayarak gidermeye çalışmıştır. Yine de bu yönde daha fazla araştırmaya ihtiyaç vardır.

Katılımcıların gruplara seçkisiz atanmaması da bir sinırlılıktır. Son-testte merkezi yönetici işlemlerinin ölçülmesi ve bu işlemlerin okuma becerisi (Butterfuss ve Kendeou, 2018) ile dil edinme becerilerini (Kapa ve Colombo, 2014) belirlediği düşünülürse, bireylerin kendi istekleri doğrultusunda dil edinme programına kayıt olmaları da bir sorundur. Gruplar arası herhangi bir farkın veya herhangi bir farkın olmamasının bireysel farkl1lıklardan olma ihtimali de vardır. Bunun bir çözümü, tek dilli bireylerin seçkisiz deney ve kontrol grubuna atanması ve deney grubundaki bireylerin dil edinme süreçlerinin bundan sonra başlamasıdır.

Bunun yanında, pasif kontrol grubu oluşturmak da (Ramos ve ark., 2017) yetersizdir. Bilişsel egzersiz araştırmalarında; örneğin bilgisayar oyunlarının biliş üzerindeki etkilerini araştıran araştırmacılar plasebo etkilerinin ortadan kaldırılmasını önermektedir (Boot ve ark., 2011; 2013). Bundan dolayı sadece pasif kontrol gruplarının ${ }^{3}$ olması yetersizdir. Aktif, yani dil eğitimi süresince farklı aktiviteler yapan; örneğin kitap okuyan, kontrol gruplarına ihtiyaç vardır. Eğer aktif kontrol ve deney grubunda pasif kontrol grubuna kıyasla iyileşme görülürse, iyileşmenin dil eğitiminden ziyade yapılan herhangi bir aktiviteden kaynaklı olduğunu görmüş oluruz. Fakat iyileşme sadece deney grubunda görülürse, bu iyileşmenin dil eğitiminden kaynaklı olduğu netleşebilir.

Deney grubu, aktif ve pasif kontrol grubu gibi farkl1 grupların olması yine bir başka sınırlılıktır. Katılımcıların hangi gruba dahil edilip edilmediklerinin bilincinde olmaları, örneğin bireyin ikinci dil öğrenme grubunda olmas1; dil eğitimin getirebileceği iyileşme doğrultusunda kat1lımcının bir beklenti içerisine girmesine neden olabilir. $\mathrm{Bu}$ beklentiler, kişilerin motivasyonunu arttırabilir ya da azaltabilir; bu da görev performanslarına yansıyabilir (Kahneman, 1973). Bundan dolayı herhangi bir iyileşmenin, yapılan dil eğitiminden ziyade katılımcının beklentisinden elde ettiği faydanın bir göstergesi olma ihtimali yüksektir (Boot ve ark., 2013). Bu sınırlılığı ortadan kaldırmak için izlenebilecek bir yol, katılımcıların deney sonrası dil eğitim programları hakkındaki beklentileri, motivasyonları ve dil eğitimi ile geçiş görev becerileri arasındaki bağlantının incelenip bu faktörlerin her iki grupta eşit olmasını sağlamaktır (Boot ve ark., 2011; 2013).

\section{Sonuç}

Günümüzde birçok kişinin birden fazla dil biliyor olması ve ayrı bir çaba harcamadan sadece dillerin kullanılması ile bilişsel becerilerin gelişebiliyor olma olasılığ 1 iki dilliliği cazip bir bilişsel egzersiz haline getirmektedir. Ancak bilişsel avantaj kuramı güncel bir tartışma konusu olmaya devam etmektedir. İki dilliliğin geçiş becerilerini geliştirebilme potansiyelinin olduğu gösterilse de tam tersini bulan araştırmalar da vardır. Bilişsel becerilerin günlük yaşamsal aktiviteler ile ilişkili olması nedeniyle, iki dilliliğin bilișsel egzersiz olup olmadığının belirlenmesi özellikle bilişsel gerileme yaşayan bireyler için önemlidir. İki dillilik araştırmalarının cevaplaması gereken pek çok soru bulunmaktadır. Bu sorulardan bir tanesi de iki dilliliğin merkezi yönetici işlemlerini nasıl etkilediği, buna ek olarak bu etkinin hangi yönde oldu-

3 Bu gruptaki katılımcılar ön-test ile son-test arası hiçbir ek aktivitede bulunmuyorlar. 
ğudur. Bir başka deyişle daha gelişmiş merkezi yönetici işlemleri olan bireyler mi ikinci bir dil edinmektedir, yoksa bu bireyler ikinci bir dil öğrendiği için mi geçiş görev becerileri gelişmektedir? Buna benzer soruları yanıtlayabilmek için dil eğitim programları içeren ve deneysel desen kullanan boylamsal araştırmalara ihtiyaç duyulmaktadır.

\section{Teșekkür}

Araştırma metninin düzenlenmesi konusunda yardımları için Uzm. Sosyal Psk. Elif Öykü Us'a teşekkür ederim.

\section{Kaynaklar}

Abutalebi, J., Canini, M., Rosa, P. A. D., Sheung, L. P., Green, D. W., \& Weekes, B. S. (2014). Bilingualism protects anterior temporal lobe integrity in aging. Neurobiology, 35, 2126-2133. https://doi. org/10.1016/j.neurobiolaging.2014.03.010

Abutalebi, J., \& Green, D. W. (2008) Control mechanis$\mathrm{ms}$ in bilingual language production: Neural evidence from language switching studies. Language and Cognitive Processes, 23(4), 557-582. https:// doi.org/10.1080/01690960801920602

Antoniou, M. (2019). The advantages of bilingualism debate. Annual Review of Linguistics, 5(1), 1-21. https://doi.org/10.1146/annurev-linguistics-011718-011820

Barac, R., \& Bialystok, E. (2012). Bilingual effects on cognitive and linguistic development: Role of language, cultural background, and education. Child Development, 83(2), 413-422. https://doi. org/10.1111/j.1467-8624.2011.01707.x

Barbu, C., Orban, S., Gillet, S., \& Poncelet, M. (2018). The impact of language switching frequency on attentional and executive functioning in proficient bilingual adults. Psychologica Belgica, 58(1), 115127. https://doi.org/10.5334/pb.392

Bell-McGinty, S., Podell, K., Franzen, M., Baird, A. D., \& Williams, M. J. (2002). Standard measures of executive function in predicting instrumental activities of daily living in older adults. International Journal of Geriatric Psychiatry, 17(9), 828-834. https://doi.org/10.1002/gps.646

Bialystok, E. (2010). Global-local and trail-making tasks by monolingual and bilingual children: Beyond inhibition. Developmental Psychology, 46(1), 93105. https://doi.org/10.1037/a0015466

Bialystok, E. (2011). Coordination of executive functions in monolingual and bilingual children. Journal of Experimental Child Psychology, 110, 461-468. https://doi.org/10.1016/j.jecp.2011.05.005

Bialystok, E., Craik F. I. M., \& Freedman, M. (2007). Bilingualism as a protection against the onset of symptoms of dementia. Neuropsychologia, 45, 459-64. https:// doi.org/10.1016/j.neuropsychologia.2006.10.009

Bialystok, E., Craik, F. I. M., \& Luk, G. (2008). Lexical access in bilinguals: Effects of vocabulary size and executive control. Journal of Neurolinguistics, 21, 522-538. https://doi.org/10.1016/j.jneuroling.2007.07.001

Bialystok, E., Craik, F. I. M., \& Ruocco, A. C. (2006). Dual-modality monitoring in a classification task: The effects of bilingualism and ageing. The Quarterly Journal of Experimental 
Psychology, 59(11), 1968-1983. https://doi. org/10.1080/17470210500482955

Bialystok, E., \& Viswanathan, M. (2009). Components of executive control with advantages for bilingual children in two cultures. Cognition, 112 (3), 494-500. https://doi.org/10.1016/j.cognition.2009.06.014

Blanco-Elorrietaa, E., Emmorey, K., \& Pylkkänena, L. (2018). Language switching decomposed through MEG and evidence from bimodal bilinguals. PNAS, 115(39), 9708-9713. www.pnas.org/cgi/ doi/10.1073/pnas.1809779115

Blanco-Elorrietaa, E., \& Pylkkänena, L. (2017). Bilingual language switching in the laboratory versus in the wild: The spatiotemporal dynamics of adaptive language control. Journal of Neuroscience, 37(37),9022-9036. https://doi.org/10.1523/ JNEUROSCI.0553-17.2017

Boot, W. R., Blakely, D. P., \& Simons, D. J. (2011). Do action video games improve perception and cognition? Frontiers in Psychology, 2(226), 1-6. PMCID: PMC3171788

Boot, W. R., Simons, D. J., Stothart, C., \& Stutts, C. (2013). The pervasive problem with placebos in psychology: Why active control groups are not sufficient to rule out placebo effects. Perspectives on Psychological Science, 8(4), 445-454. https://doi. org/10.1177/1745691613491271

Brito, N., \& Barr, R. (2014). Flexible memory retrieval in bilingual 6-month-old infants. Developmental Psychobiology, 56(5), 1156-1163. https://doi. org/10.1002/dev.21188

Brito, N. H., Murphy, E. R., Vaidya, C., \& Barr, R. (2016). Do bilingual advantages in attentional control influence memory encoding during a divided attention task? Bilingualism: Language and Cognition, 19(3), 621-629. https://doi.org/10.1017/ S1366728915000851

Butterfuss, R., \& Kendeou, P. (2018). The role of executive functions in reading comprehension. Educational Psychology Review, 30(3), 801-826. https:// doi.org/10.1007/s10648-017-9422-6

Cahn-Weiner, D. A., Boyle, P. A., \& Malloy, P. F. (2007). Tests of executive function predict instrumental activities of daily living in community-dwelling older individuals. Applied Neuropsychology, 9(3), 187-191. https://doi.org/10.1207/ S15324826AN0903 8

Christoffels, I. K., de Haan, A. M., Steenbergen, L., van den Wildenberg, W. P. M., \& Colzato, L. S. (2015). Two is better than one: Bilingual education promotes the flexible mind. Psychological Research, 79, 371379. https://doi.org/10.1007/s00426-014-0575-3
Chung-Fat-Lim, A., Himel, C., \& Bialystok, E. (2018). The impact of bilingualism on executive function in adolescents. International Journal of Bilingualism, 23(6), 1278-1290. https://doi. org/10.1177/1367006918781059

Costa, A., Hernández, M., Costa-Faidella, J., \& Sebastián-Gallés, N. (2009). On the bilingual advantage in conflict processing: Now you see it, now you don't. Cognition, 113(2), 135-149. https://doi.org/10.1016/j.cognition.2009.08.00

Craik, F. I. M., Bialystok, E., \& Freedman, M. (2010). Delaying the onset of Alzheimer's disease. Bilingualism as a form of cognitive reserve. Neurology 75(19), 1726-9. https://doi.org/10.1212/WNL. 0b013e3181fc2a1c

Crone, E. A., Bunge, S. A., van der Molen, M. W., \& Ridderinkhof, K. R. (2006). Switching between tasks and responses: A developmental study. Developmental Science, 9(3), 278-287. https://doi. org/10.1111/j.1467-7687.2006.00490.x

de Baene, W., Duyck, W., Brass, M., \& Carreiras, M. (2015). Brain circuit for cognitive control is shared by task and language switching. Journal of Cognitive Neuroscience 27(9), 1752-1765. https://doi. org/10.1162/jocn_a_00817

de Bruin, A., Treccani, B., \& Della Sala, S. (2014). Cognitive advantages in bilingualism: An example of publication bias. Psychological Science, 26(1), 1-9, https://doi.org/10.1177/0956797614557866

D’Souza, D., Brady, D., Haensel, J. X., \& D'Souza, H. (2020). Is mere exposure enough? The effects of bilingual environments on infant cognitive development. Royal Society Open Science, 7(2), 180191. https://doi.org/10.1098/rsos.180191

Diebold, A.R. Jr. (1961). Incipient bilingualism. Language, 37(1), 97-112.

Dong, Y., \& Lui, Y. (2016). Classes in translating and interpreting produce differential gains in switching and updating. Frontiers in Psychology, 7(1297). https://doi.org/10.3389/fpsyg.2016.01297

Gathercole, V. C. M., Kennedy, I., \& Thomas, E. M. (2016). Socioeconomic level and bilinguals' performance on language and cognitive measures. Bilingualism: Language and Cognition, 19(5), 1057-1078. https://doi.org/10.1017/ S1366728915000504

Gollan, T. H., Salmon, D. P., Montoya, R. I., \& Galasko, D. R. (2011). Degree of bilingualism predicts age of diagnosis of Alzheimer's disease in low-education but not in highly educated Hispanics. Neuropsychologia, 49(14), 38263830. https://doi.org/10.1016/j.neuropsychologia.2011.09.041 
Green, D.W., \& Abutalebi, J. (2013). Language control in bilinguals: The adaptive control hypothesis. Journal of Cognitive Psychology, 25(5), 515-530. https://doi.org/10.1080/20445911.2013.796377

Green, C. S., \& Bavelier, D. (2008). Exercising your brain: A review of human brain plasticity and training-induced learning. Psychological Aging, 23(4), 692-701. https://doi.org/10.1037/a0014345

Grosjean, F. (2013). Bilingual and monolingual language modes. The Encyclopedia of Applied Linguistics. https://doi.org/10.1002/9781405198431. wbeal0090

Grosjean, F., \& Miller, J. L. (1994). Going in and out of languages: an example of bilingual flexibility. $P S-$ ychological Science, 5(4), 201-206. https://www. jstor.org/stable/40063102

Hartanto, A., \& Yang, H. (2016). Disparate bilingual experiences modulate task switching advantages: A diffusion-model analysis of the effects of interactional context on switch costs. Cognition, 150, 10-19. https://doi.org/10.1016/j.cognition.2016.01.016

Hernandez, M., Martin, C. D., Barcelo, F., \& Costa, A. (2013). Where is the bilingual advantage in task-switching? Journal of Memory and Language, 69, 257-276. https://doi.org/10.1016/j. jml.2013.06.004

Hosoda, C., Hanakawa, T., Nariai, T., Ohno, K., \& Honda, M. (2012). Neural mechanisms of language switch. Journal of Neurolinguistics 25, 44-61. https://doi.org/10.1016/j.jneuroling.2011.08.007

Houtzager, N., Lowie, W., Sprenger, S., \& de Bot, K. (2015). A bilingual advantage in task switching? Age-related differences between German monolinguals and Dutch-Frisian bilinguals. Bilingualism: Language and Cognition. Advance online publication. https://doi.org/10.1017/S1366728915000498

Ibrahim, R., Shoshani, R., Prior, A., \& Share, D. (2013). Bilingualism and measures of spontaneous and reactive cognitive flexibility. Psychology, 4(7A), 1-10.

Jaekel, N., Jaekel, J., Willard, J., \& Leyendecker, B. (2019). No evidence for effects of Turkish immigrant children's bilingualism on executive functions. PLoS ONE 14(1): e0209981. https://doi. org/10.1371/journal.pone.0209981

Jevtović, M., Duñabeitia, J. A., \& de Bruin, A. (2019). How do bilinguals switch between languages in different interactional contexts? A comparison between voluntary and mandatory language switching. Bilingualism: Language and Cognition, 1-13. https://doi.org/10.1017/S1366728919000191

Kahneman, D. (1973). Attention and effort. Englewood Cliffs, NJ: Prentice-Hall.
Kapa, L. L., \& Colombo, J. (2014). Executive function predicts artificial language learning. Journal of Memory and Language, 76, 237-252. https://doi. org/10.1016/j.jml.2014.07.004

Kang, C., Fu, Y., Wu, J., Ma, F., Lu, C., \& Guo, T. (2017). Short-term language switching training tunes the neural correlates of cognitive control in bilingual language production. Human Brain Mapping, 38, 5859-5870. https://doi.org/10.1002/hbm.23765

Kaushanskaya, M., Blumenfeld, H. K., \& Marian, V. (2011). The relationship between vocabulary and short-term memory measures in monolingual and bilingual speakers. International Journal of Bilingualism, 15(4), 408-425. https://doi. org/10.1177/1367006911403201

Khodos, I., \& Moskovsky, C. (2020). Dimensions of bilingualism promoting cognitive control: Impacts of language context and onset age of active bilingualism on mixing and switching costs. Linguistic Approaches to Bilingualism. Advanced online publication. http://doi.org/10.1075/lab.19064.kho

Kiesel, A., Steinhauser, M., Wendt, M., Falkenstein, M., Jost, K., Philipp, A. M., \& Koch, I. (2010). Control and interference in task switching-A review. Psychological Bulletin, 136(5), 849-874. https://doi. org/10.1037/a0019842

Kovács, Á. M., \& Mehler, J. (2009). Cognitive gains in 7-month-old bilingual infants. PNAS Proceedings of the National Academy of Sciences of the United States of America, 106(16), 6556-6560. https://doi. org/10.1073/pnas.0811323106

Liddicoat, A. (1991). Bilingualism: An introduction. In Bilingualism and Bilingual Education. Melbourne: NLIA.

Liu, C., Yang, C. L., Jiao, L., Schwieter, J. W., Sun, X., \& Wang, R. (2019). Training in language switching facilitates bilinguals' monitoring and inhibitory control. Frontiers in Psychology, 10(1839). https:// doi.org/10.3389/fpsyg.2019.01839

Luk, G., Green, D. W., Abutalebi, J., \& Grady, C. (2012). Cognitive control for language switching in bilinguals: A quantitative meta-analysis of functional neuroimaging studies. Language and Cognitive Processes, 27(10), 1479-1488. https://doi.org/10.1 080/01690965.2011.613209

Luo, L., Craik, F. I. M., Moreno, S., \& Bialystok, E. (2013). Bilingualism interacts with domain in a working memory task: Evidence from aging. Psychology and Aging, 28(1), 28-34. https://doi. org/10.1037/a0030875

Mackey, W. F. (2001). The description of bilingualism. In L. Wei (Ed.), The bilingualism reader (pp. $22-$ 51). New York, NY: Routledge. 
Marzecova, A., Bukowski, M., Correa, A., Boros, M., Lupianez, J., \& Wodniecka, Z. (2013). Tracing the bilingual advantage in cognitive control: The role of flexibility in temporal preparation and category switching. Journal of Cognitive Psychology, 25(5), 1-19, https://doi.org/10.1080/20445911.2013.8093.48

Miyake, A., Friedman, N. P., Emerson, M. J., Witzki, A. H., Howerter, A., \& Wager, T. D. (2000). The unity and diversity of executive functions and their contributions to complex frontal lobe tasks: A latent variable analysis. Cognitive Psychology, 41, 49-100. https://doi.org/10.1006/cogp.1999.0734

Monsell, S. (2003). Task switching. Trends in Cognitive Science, 7(3), 134-140. https://doi.org/10.1016/ S1364-6613(03)00028-7

Mor, B., Yitzhaki, S., \& Prior, A. (2014). The joint effect of bilingualism and ADHD on executive functions. Journal of Attention Disorders, 19(6), 527-541. https://doi.org/10.1177/1087054714527790

Moradzadeh, L., Blumenthal, G., \& Wisehearta, M. (2014). Musical training, bilingualism, and executive function: A closer look at task switching and dual-task performance. Cognitive Science, 39, 9921020. https://doi.org/10.1111/cogs.12183

Morton, J. B., \& Harper, S. N. (2007). What did Simon say? Revisiting the bilingual advantage. Developmental Science, 10(6), 719-726. https://doi.org/10.1111/j.1467-7687.2007.00623.x

Nichols, E. S., Wild, C. J., Stojanoski, B., Battista, M.E., \& Owen, A. M. (2020). Bilingualism affords no general cognitive advantages: A population study of executive function in 11,000 people. $P S$ ychological Science, 31(5), 548-567. https://doi. org/10.1177/0956797620903113

Nicoladis, E., Hui, D., \& Wiebe, S. A. (2018). Language dominance and cognitive flexibility in French-English bilingual children. Frontiers in Psychology, 9 (1697). https://doi.org/10.3389/fpsyg.2018.01697

Oschwald, J., Schättin, A., von Bastian, C., \& Souza, A. S. (2018). Bidialectalism and bilingualism: Exploring the role of language similarity as a link between linguistic ability and executive control. Frontiers in Psychology, 9 (1997). https://doi. org/10.3389/fpsyg.2018.01997

Paap, K. R., \& Greenberg, Z. I. (2013). There is no coherent evidence for a bilingual advantage in executive processing. Cognitive Psychology, 66(2), 232-258. https://doi.org/10.1016/j.cogpsych.2012.12.002

Paap, K. R., Johnson, H. A., \& Sawi, O. (2014). Bilingual advantages in executive functioning: problems in convergent validity, discriminant validity, and the identification of the theoretical constructs. Frontiers in Psychology, 5(962), 43-51, https://doi. org/10.3389/fpsyg.2014.00962

Paap, K. R., Johnson, H. A., \& Sawi, O. (2015). Bilingual advantages in executive functioning either do not exist or are restricted to very specific and undermined circumstances. Cortex, 69, 265-278. https://doi.org/10.1016/j.cortex.2015.04.014

Paap, K. R., Johnson, H. A., \& Sawi, O. (2016). Should the search for bilingual advantages in executive functioning continue? Cortex, 74, 305-314. https:// doi.org/10.1016/j.cortex.2015.09.010

Paap, K. R., Myuz, H. A., Anders, R. T., Bockelman, M. F., Mikulinsky, R., \& Sawi, O. M. (2017). No compelling evidence for a bilingual advantage in switching or that frequent language switching reduces switch cost. Journal of Cognitive Psychology, 29(2), 89-112. https://doi.org/10.1080/20445 911.2016.1248436

Paap, K. R., \& Sawi, O. (2014). Bilingual advantages in executive functioning: problems in convergent validity, discriminant validity, and the identification of the theoretical constructs. Frontiers in Psychology, 5(962). https://doi.org/10.3389/fpsyg.2014.00962

Papageorgiou, A., Bright, P., Tomas, E. P., \& Filippi, R. (2018). Evidence against a cognitive advantage in the older bilingual population. Quarterly Journal of Experimental Psychology, 1-10. https://doi. org/10.1177/1747021818796475

Park, J., Ellis Weismer, S., \& Kaushanskaya, M. (2018). Changes in executive function over time in bilingual and monolingual school-aged children. Developmental Psychology, 54(10), 1842-1853. https:// doi.org/10.1037/dev0000562

Prior, A., \& Gollan, T.H. (2011). Good language-switchers are good task-switchers: Evidence from Spanish-English and Mandarin-English bilinguals. Journal of the International Neuropsychological Society, 17,682-691. https://doi.org/10.1017/ S1355617711000580

Prior, A., \& Gollan, T. H. (2013). The elusive link between language control and executive control: A case of limited transfer. Journal of Cognitive Psychology, 25(5), 622-645. https://doi.org/10.1080/2044 5911.2013 .821993

Prior, A., \& Macwhinney, B. (2010). A bilingual advantage in task switching. Bilingualism: Language \& Cognition, 13(2), 253-262. https://doi. org/10.1017/S1366728909990526

Qu, L., Low, J. J. W., Zhang, T., Li, H., \& Zelazo, P. D. (2015). Bilingual advantage in executive control when task demands are considered. Bilingualism: Language and Cognition, 19(2), 1-17. https://doi. org/10.1017/S1366728914000376. 
Ramos, S., García, Y. F., Antón, E., Casaponsa, A., \& Duñabeitia, J. A. (2017). Does learning a language in the elderly enhance switching ability? Journal of Neurolinguistics, 43, 39-48. https://doi.org/10.1016/j.jneuroling.2016.09.001

Rodríguez-Pujadas, A., Sanjuán, A., Ventura-Campos, N., Román, P., Martin, C., Barceló, F., ve ark. (2013). Bilinguals use language-control brain areas more than monolinguals to perform non-linguistic switching tasks. PLoS ONE 8(9): e73028. https:// doi.org/10.1371/journal.pone.0073028

Rubin, O., \& Meiran, N. (2005). On the origins of the task mixing cost in the cuing task-switching paradigm. Journal of Experimental Psychology: Learning, Memory, and Cognition, 31(6), 1477-1491. https://doi.org/10.1037/0278-7393.31.6.1477

Schroeder, S. R., \& Marian, V. (2012). A bilingual advantage for episodic memory in older adults. Journal of Cognitive Psychology, 24(5), 591-601. https://doi.org/10.1080/20445911.2012.669367

Schweizer, T. A., Ware, J., Fischer, C. E., Craik, F. I. M, \& Bialystok, E. (2012). Bilingualism as a contributor to cognitive reserve: evidence from brain atrophy in Alzheimer's disease. Cortex, 48(8), 991-6. https://doi.org/10.1016/j.cortex.2011.04.009

Shulley, L. J., \& Shake, M. C. (2016). Investigating the relationship between bilingualism, cognitive control, and mind wandering, Journal of Cognitive Psychology, 28(3), 257-274. https://doi.org/10.1080/ 20445911.2015.1128438

Sörman, D. E., Hansson, P., \& Ljungberg, J. K. (2019). Different features of bilingualism in relation to executive functioning. Frontiers in Psychology, 10(269). https://doi.org/10.3389/fpsyg.2019.00269

Soveri, A., Rodriguez-Fornells, A., \& Laine, M. (2011). Is there a relationship between language switching and executive functions in bilingualism? Introducing a within-group analysis approach. Frontiers in Psychology, 183(2). https://doi.org/10.3389/fpsyg.2011.00183

Tao, L., Taft, M., \& Gollan, T. (2015). The bilingual switching advantage: Sometimes related to bilingual proficiency, sometimes not. Journal of the International Neuropsychological Society, 21(7), 531-544. https://doi.org/10.1017/S1355617715000521

Timmer, K., Calabria, M., \& Costa, A. (2019). Non-linguistic effects of language switching training. Cognition, 182, 14-24. https://doi.org/10.1016/j.cognition.2018.09.001

Timmermeister, M., Leseman, P., Wijnen, F., \& Blom, E. (2020). No bilingual benefits despite relations between language switching and task switching. Frontiers in Psychology, 11, 1832. https://doi. org/10.3389/fpsyg.2020.01832
Tse, C.-S., \& Altarriba, J. (2015). Local and global task switching costs in bilinguals who vary in second language proficiency. The American Journal of Psychology, 128(1), 89-106. https://doi.org/10.5406/ amerjpsyc.128.1.0089

Tuncay, F. Ö., \& Fertelli, T. K. (2018). Yaşlılarda bilişsel işlevlerin günlük yaşam aktiviteleri ve yaşam doyumu ile ilişkisi. Dokuz Eylül Üniversitesi Tıp Fakültesi Dergisi, 32(3), 190-183. https://doi. org/10.5505/deutfd.2018.82712

Vinerte, S., \& Sabourin, L. (2015). Bilingualism and cognitive control: The ANT in a Canadian context. http://cla-acl.ca/wp-content/uploads/Vinerte_Sabourin-2015.pdf.

von Bastian, C. C., Souza, A. S., \& Miriam, G. (2015). No evidence for bilingual cognitive advantages: A test of four hypotheses. Journal of Experimental Psychology General, 145(2), 246-258. https://doi. org/10.1037/xge0000120

Weissberger, G. H., Gollan, T., Bondi, M. W., Clark, L. R., \& Wierenga, C. E. (2015). Language and task switching in the bilingual brain: Bilinguals are staying, not switching, experts. Neuropsychologia, 66, 193-203. https://doi.org/10.1016/j.neuropsychologia.2014.10.037

Willis, S. L., \& Schaie, K. W. (2009). Cognitive training and plasticity: Theoretical perspective and methodological consequences. Restorative Neurology and Neuroscience, 27(5): 375-389. https:/doi. org/10.3233/RNN-2009-0527

Wiseheart, M., Viswanathan, M., \& Bialystok, E. (2014). Flexibility in task switching by monolinguals and bilinguals. Bilingualism: Language and Cognition, 19(1), 1-6. https://doi.org/10.1017/ S1366728914000273

Woumans, E., van Herck, S., \& Struys, E. (2019). Shifting gear in the study of the bilingual advantage: Language switching examined as a possible moderator. Behavioral Sciences, 9(86). https://doi. org $/ 10.3390 /$ bs 9080086

Woumans, E. Surmont, J., Struys, E., \& Duyck, W. (submitted to Language Learning). Children attending bilingual kindergarten school become smarter.

Wu, J., Kang, C., Ma, F., Gao, X., \& Guo, T. (2018). The influence of short-term language-switching training on the plasticity of the cognitive control mechanism in bilingual word production. Quarterly Journal of Psychology, 71(10), 2115-2128. https:// doi.org/10.1177/1747021817737520

Xie, Z. (2014). Second-language proficiency, language use, and mental set shifting in cognitive control among unbalanced Chinese- English bilinguals. Sage Open, 1-10. https://doi. org/10.1177/2158244014563040 
Yang, H., Hartanto, A., \& Yang, S. (2018). Bilingualism confers advantages in task switching: Evidence from the dimensional change card sort task. Bilingualism: Language and Cognition 21(5), 2018, 1091-1109. https://doi.org/10.1017/ S136672891700044X

Yim, O., \& Bialystok, E. (2012). Degree of conversational code-switching enhances verbal task switching in Cantonse-English bilinguals. Bilingualism: Language and Cognition, 15(4), 873-883. https://doi. org $/ 10.1017 / \mathrm{S} 1366728912000478$

Zuninia, R. A. L., Morrison, C., Kousaieb, S., \& Taler, V. (2019). Task switching and bilingualism in young and older adults: A behavioral and electrophysiological investigation. Neuropsychologia, 133. https://doi.org/10.1016/j.neuropsychologia.2019.107186 


\title{
Summary \\ Bilingualism and Task Switching: The Need for Experimental Designs
}

\author{
İlmiye Seçer ${ }^{1}$ \\ Koç University
}

Bilingualism can be classified as the situation where individuals acquire a second language (Diebold, 1961) and regularly use their two languages in daily life for communication purposes (Grosjean \& Miller, 1994). A number of facets such as second language proficiency in writing, speaking, reading, and listening, second language use of frequency and context (e.g., at home, work, or school), frequency of switching between languages and code-switching are determinants of bilingualism (MacKey, 2001). In addition, age of second language acquisition allows individuals to be further categorised as sequential early or late bilingual. Individuals who acquire their second language after the acquisition of their first language yet before the age of six are termed as sequential early bilingual and those after the age of six as sequential late bilingual (Tao et al., 2015). However, when individuals are exposed to two languages from birth, they are considered to be simultaneous bilinguals and both languages are deemed to be the person's first language (McLaughlin,1984, as cited in Liddicoat, 1991).

Cognitive skills in particular executive functions (i.e., inhibition, monitoring and swicthing) (Miyake et al., 2000) are related to the effective performance of daily activities such as managing one's medication and finances (Bell-McGinty et al., 2002; Cahn-Weiner et al., 2007), rendering it of vital importance to investigate ways to maintain and enhance such skills. Studies conducted to this effect reveal that everyday experiences, environmental simulations, and cognitive training (e.g., sports, music, \& video games) ameliorate an individual's latent cognitive potential (for review see Green \& Bavelier, 2008; Willis \& Schaie, 2009). In this sense, bilingualism, which requires the coordination of two languages by inhibiting one language to speak in the other and switching between the two languages is considered to be an effective form of cognitive training to enhance executive functions (Bialystok, 2011).

The bilingual advantage hypothesis has received considerable support from correlational and neuroimag- ing studies (Abutalebi et al., 2014; Bialystok et al., 2006; Bialystok \& Viswanathan, 2009; Schroeder \& Marian, 2012; Schweizer et al., 2012). Bilinguals have been found to outperform monolinguals on a range of cognitive tasks (Antoniou, 2019) that mainly tap processes of executive functions (i.e., inhibition of dominant responses, shifting between mental sets, and the monitoring and updating of information in working memory (Miyake et al., 2000). On the other hand, other studies, do not find a bilingual advantage in cognition (Brito et al., 2016; Kaushanskaya et al., 2011; Luo et al., 2013; Nichols et al., 2020; Papageorgiou, et al., 2018) and attribute such effects to publication bias, in which significant compared to non-significant findings are published to a greater degree (de Bruin et al., 2014), to underpowered designs due to small sample sizes (Paap et al., 2015; Paap, et al., 2016) and a lack of control of confounding variables such as socio-economic status, ethnicity, and linguistic factors between the groups (Gathercole et al., 2016; Morton \& Harper, 2007; Paap \& Greenberg, 2013). It has further been indicated that uncovering the effects of second language use is more difficult in younger adults who are at their peak cognitively (Vinerte \& Sabourin, 2015), especially when less demanding cognitive tasks are used as outcome measures (Ibrahim et al., 2013; Qu et al., 2015).

Overall, while some studies find a relationship between bilingualism and cognition others do not, thus the existence of a bilingual advantage remains a controversial topic. One cognitive skill expected to improve via bilingualism is task switching abilities as the mechanisms of dual language coordination that is inhibition, monitoring and switching overlap with those of task switching (Abutalebi \& Green, 2008; Costa et al., 2009). The possibility of improved cognitive skills and a delay in the onset of dementia render it important to carry out further studies in relation to the cognitive effects of bilingualism. Therefore, an objective of the current paper is to provide an overview of past studies that have ex-

Address for Correspondence: ${ }^{1}$ Lecturer İlmiye Seçer, Koç University, College of Social Sciences and Humanities, Department of Psychology, Sariyer / Istanbul.

E-mail: secer.ilmiye@gmail.com 
amined the cognitive effects of bilingualism and suggest directions for future research regarding bilingualism and task switching. The following section will expand on task switching abilities.

\section{Measurement of Task Switching Abilities}

Execution of a given task requires the activation of a task set, that is, the representation of the relevant task stimuli and response (S-R) mappings (Kiesel et al., 2010). Task switching abilities thus require the effective allocation of attention to the task at hand, activation of the relevant rule, and appropriate response selection amongst other options (Abutalebi \& Green, 2008; Monsell, 2003; Rubin \& Meiran, 2005). Therefore, task switching skills require effective processes of switching, monitoring and inhibition (Abutalebi \& Green, 2008). To assess task switching ability, individuals respond to perceptual stimuli using the same rule on repetition trials (i.e., non-switch trials) and alternate between rules on mixed task blocks (i.e., includes both switch and non-switch trials), in which two types of cost: switch and mixing, are calculated. A larger cost is indicative of lower performance, that is, increased response times and error rates (Rubin \& Meiran, 2005).

\section{Bilingualism, Language Switching and Task Switching Abilities}

Considering that cognitive control, task switching and language switching abilities utilize similar brain regions, that is, left inferior frontal gyrus and caudate nucleus (Hosoda et al., 2012), precuneus, posterior cingulum, fusiform gyrus, pre-supplementary motor region, calcarine fissure (de Baene et al., 2015), and insular and basal ganglia (Weissberger et al., 2015), it is expected that individuals who engage in language switching will have improved task switching abilities (Paap et al., 2017). However, the exact nature of the effect of bilingualism on task switching abilities is unclear.

\section{Correlational Research}

Correlational studies have revealed mixed findings with regard to the positive effects of bilingualism on task switching abilities. Some studies (Christoffels et al., 2015; Marzecova et al., 2013; Prior \& Gollan, 2011; Prior \& Macwhinney, 2010; Tao et al., 2015; Woumans et al., 2019; Yang et al., 2018; Zunini et al., 2019) show that use of two languages foster such skills while others (Chung-Fat-Lim et al., 2018; Hernández et al., 2013; Jaekel et al., 2018; Mor et al., 2014; Moradzadeh et al., 2014; Nicoladis et al., 2018; Paap \& Greenberg, 2013; Paap et al., 2017; Paap \& Sawi, 2014; Rodriguez-Pujada et al., 2013; Shulley \& Shake, 2016; Sörman et al., 2019; von Bastian et al., 2015) find no effect.

\section{Language Switching Training}

Considering that executive functions aid in the acquisition of a second language (Kapa \& Colombo, 2014), an issue that arises with correlational research is that the direction of the relationship between language use and task switching abilities is unclear. One question that therefore requires clarification is whether individuals have better executive functions because they had acquired a second language or whether people who have better executive functions learn a second language? To this end, some studies (Dong \& Liu, 2016; Kang et al., 2017; Liu et al., 2019; Prior \& Gollan, 2013; Timmer et al., 2018; Wu et al., 2018) have examined the effect of language switching training on task switching abilities, which show of mixed findings. Some studies (Kang et al., 2013; Liu et al., 2019; Trimmer et al., 2018) find that language switching training improves task switching abilities while others (Prior \& Gollan, 2013; Wu et al., 2018) show of no significant effect.

\section{Language Learning}

To unravel whether bilingualism can lead to cognitive gains, there is a need for longitudinal studies. To fulfil this gap, Ramos et al. (2017) has examined whether language learning via a course can enhance task switching abilities in older adults. Findings of this study showed older adults enrolled in a language course did not have improved task switching abilities compared to those who did not enrol in a language course, indicating that language learning does not enhance skills of task switching.

\section{Discussion}

Overall, findings of past studies reveal that effect of bilingualism on task switching abilities fluctuate. In discerning the effects of language use on task switching abilities, frequency of language use and switching between languages has been extensively examined. It is recommended that the form of language switching such as switching between languages in written communication is also assessed. This is because findings of studies with toddlers have shown improved task engagement and disengagement abilities following only auditory exposure to two languages (D'Souza et al., 2020; Kovacs $\&$ Mehler, 2009). Such findings suggest that the mechanisms of dual language coordination go beyond verbal language use. In light of current findings, it is possible to say that future research is needed to determine the circumstances of bilingual advantages (if any exist). To further this line of research there is therefore a need for cause-effect studies. The following section will expand on the need for such studies and suggest possible methodological improvements. 


\section{Future Directions: Experimental Designs}

Overall, the majority of the studies that have examined bilingualism and task switching abilities reveal of a beneficial effect. However, some of the issues present in the current studies include the lack of: pre-tests (Prior \& Gollan, 2013), control groups (Kang et al., 2013 Liu et al., 2019; Wu et al., 2018) and random assignment of participants to the experimental and control groups (Ramos et al., 2017). One alternative way to shed light onto the matter and clarify the effect of bilingualism on cognition is the use of experimental designs. This methodology requires for a group of participants equal on a number of demographic variables to be randomly allocated to the experimental and control group once assessed for their task switching abilities. Participants in the experimental group will be required to start learning the second language in question then after for which task switching abilities would be assessed for both groups a second time.

The lack of pre-tests is an important limitation as it limits the ability to determine the extent of change in task switching abilities following language acquisition. It is also possible that prior to language acquisition the experiment groups' executive functions were improved and that any difference observed between the groups do not reflect language use. On the other hand, without pretests it is not possible to say that language acquisition has had no effect on cognition as it may be that there is a trend towards an improvement yet cannot be observed due to factors such as limited training. It is therefore important to have measurements of people's cognitive abilities before and after language acquisition.

Some studies (Kang et al., 2013, Liu et al., 2019; Wu et al., 2018) have included a pre-test and post-test design in the measurement of task switching abilities, yet, their sample only consisted of bilingual participants. In such an instance, the lack of a control group (i.e., monolingual individuals) is a limiting factor. Inclusion of control groups will enable the assessment of whether any reduction in switching or mixing costs are attributable to language use. Otherwise, it is possible that any activity other than language use may lead to an improvement in task switching abilities. In their study, Liu et al. (2019) included a control group that did not require language switching training, yet, further research in this regard are needed.

The lack of random assignment to groups is also a limitation. Considering that executive functions are related to reading ability (Butterfuss \& Kendeou, 2018) and language learning ability (Kapa \& Colombo, 2014), individuals already enrolled in a language learning program is problematic. Any difference or the lack of difference between groups may be attributable to individual differences. One way to overcome this is to randomly assign monolingual individuals to the experimental and control group in which language acquisition for the experimental group will begin herein after.

The use of passive control groups (Ramos et al., 2017) is also inadequate. Studies that examine cognitive training such as the effects of video game training on cognition state the importance of eliminating placebo effects (Boot et al.., 2011; 2013). For this reason, there is a need for active control groups in which participants engage in an alternative activity (e.g., reading a book) for the same extent of time that the experimental group is involved in learning a second language. If the active control group and the experimental group show improvement in comparison to the passive control group, we could postulate that the improvement is a result of any kind of activity rather than language use. However, if the improvement is seen in only the experimental group then it is possible to conclude that language learning drove the group differences.

Other issues that need to be resolved is participants expectation based on their group allocation. For example, the fact that participants will be aware that they are assigned to the language learning group may lead to expectation for how language learning may influence their cognitive performance. Such expectations can increase or decrease participants motivation which can influence their task performance (Kahneman, 1973). For this reason, it is possible that improvement is related to participants expectation than to the actual learning of a second language per se. (Boot et al., 2013). To overcome this limitation, it is important to assess via a post-experiment questionnaire participants expectation regarding language learning, their level of motivation, and knowledge regarding the link between language learning and task switching and ensure that groups are equated on these aspects (Boot et al., 2011; 2013).

\section{Conclusion}

The bilingual advantage hypothesis is a current topic of debate for which there are several fundamental questions that still need to be addressed. Some questions include the need to determine how bilingualism influences executive functions and to decide on the direction of the effect. In other words, it is important to discern whether people with improved executive functions learn a second language or whether learning a second language leads to an improvement in executive functions. To address such questions and those alike there is a need for studies that are of longitudinal experimental design that include language learning programs. 


\section{References}

Abutalebi, J., Canini, M., Rosa, P. A. D., Sheung, L. P., Green, D. W., \& Weekes, B. S. (2014). Bilingualism protects anterior temporal lobe integrity in aging. Neurobiology, 35, 2126-2133. https://doi. org/10.1016/j.neurobiolaging.2014.03.010

Abutalebi, J., \& Green, D. W. (2008) Control mechanisms in bilingual language production: Neural evidence from language switching studies. Language and Cognitive Processes, 23(4), 557-582. https:// doi.org/10.1080/01690960801920602

Antoniou, M. (2019). The advantages of bilingualism debate. Annual Review of Linguistics, 5(1), 1-21. https://doi.org/10.1146/annurev-linguistics-011718-011820

Bialystok, E. (2011). Coordination of executive functions in monolingual and bilingual children. Journal of Experimental Child Psychology, 110, 461468. https://doi.org/10.1016/j.jecp.2011.05.005

Bialystok, E., Craik, F. I. M., \& Ruocco, A. C. (2006). Dual-modality monitoring in a classification task: The effects of bilingualism and ageing. The Quarterly Journal of Experimental Psychology, 59(11), 1968-1983. https://doi. org/10.1080/17470210500482955

Bialystok, E., \& Viswanathan, M. (2009). Components of executive control with advantages for bilingual children in two cultures. Cognition, 112 (3), 494-500. https://doi.org/10.1016/j.cognition.2009.06.014

Boot, W. R., Blakely, D. P., \& Simons, D. J. (2011). Do action video games improve perception and cognition? Frontiers in Psychology, 2(226), 1-6. PMCID: PMC3171788

Boot, W. R., Simons, D. J., Stothart, C., \& Stutts, C. (2013). The pervasive problem with placebos in psychology: Why active control groups are not sufficient to rule out placebo effects. Perspectives on Psychological Science, 8(4), 445-454. https://doi. org/10.1177/1745691613491271

Brito, N. H., Murphy, E. R., Vaidya, C., \& Barr, R. (2016). Do bilingual advantages in attentional control influence memory encoding during a divided attention task? Bilingualism: Language and Cognition, 19(3), 621-629. https://doi.org/10.1017/ S1366728915000851

Butterfuss, R., \& Kendeou, P. (2018). The role of executive functions in reading comprehension. Educational Psychology Review, 30(3), 801-826. https:// doi.org/10.1007/s10648-017-9422-6

Christoffels, I. K., de Haan, A. M., Steenbergen, L., van den Wildenberg, W. P. M., \& Colzato, L. S. (2015).
Two is better than one: Bilingual education promotes the flexible mind. Psychological Research, 79, 371379. https://doi.org/10.1007/s00426-014-0575-3

Chung-Fat-Lim, A., Himel, C., \& Bialystok, E. (2018). The impact of bilingualism on executive function in adolescents. International Journal of Bilingualism, 23(6), 1278-1290. https://doi. org/10.1177/1367006918781059

Costa, A., Hernández, M., Costa-Faidella, J., \& Sebastián-Gallés, N. (2009). On the bilingual advantage in conflict processing: Now you see it, now you don't. Cognition, 113(2), 135-149. https://doi. org/10.1016/j.cognition.2009.08.00

de Baene, W., Duyck, W., Brass, M., \& Carreiras, M. (2015). Brain circuit for cognitive control is shared by task and language switching. Journal of Cognitive Neuroscience 27(9), 1752-1765. https://doi. org/10.1162/jocn_a_00817

de Bruin, A., Treccani, B., \& Della Sala, S. (2014). Cognitive advantages in bilingualism: An example of publication bias. Psychological Science, 26(1), 1-9, https://doi.org/10.1177/0956797614557866

Dong, Y., \& Lui, Y. (2016). Classes in translating and interpreting produce differential gains in switching and updating. Frontiers in Psychology, 7(1297). https://doi.org/10.3389/fpsyg.2016.01297

D’Souza, D., Brady, D., Haensel, J. X., \& D’Souza, H. (2020). Is mere exposure enough? The effects of bilingual environments on infant cognitive development. Royal Society Open Science, 7(2), 180191. https://doi.org/10.1098/rsos.180191

Gathercole, V. C. M., Kennedy, I., \& Thomas, E. M. (2016). Socioeconomic level and bilinguals' performance on language and cognitive measures. $\mathrm{Bi}$ lingualism: Language and Cognition, 19(5), $1057-$ 1078. https://doi.org/10.1017/S1366728915000504.

Green, C. S., \& Bavelier, D. (2008). Exercising your brain: A review of human brain plasticity and training-induced learning. Psychological Aging, 23(4), 692-701. https://doi.org/10.1037/a0014345.

Grosjean, F., \& Miller, J. L. (1994). Going in and out of languages: an example of bilingual flexibility. Psychological Science, 5(4), 201-206. https://www. jstor.org/stable/40063102

Hernandez, M., Martin, C. D., Barcelo, F., \& Costa, A. (2013). Where is the bilingual advantage in task-switching? Journal of Memory and Language, 69, 257-276. https://doi.org/10.1016/j. jml.2013.06.004

Hosoda, C., Hanakawa, T., Nariai, T., Ohno, K., \& Honda, M. (2012). Neural mechanisms of language switch. Journal of Neurolinguistics 25, 44-61. https://doi.org/10.1016/j.jneuroling.2011.08.007 
Ibrahim, R., Shoshani, R., Prior, A., \& Share, D. (2013). Bilingualism and measures of spontaneous and reactive cognitive flexibility. Psychology, 4(7A), 1-10.

Jaekel, N., Jaekel, J., Willard, J., \& Leyendecker, B. (2019). No evidence for effects of Turkish immigrant children's bilingualism on executive functions. PLoS ONE 14(1): e0209981. https://doi. org/10.1371/journal.pone.0209981

Kahneman, D. (1973). Attention and effort. Englewood Cliffs, NJ: Prentice-Hall.

Kapa, L. L., \& Colombo, J. (2014). Executive function predicts artificial language learning. Journal of Memory and Language, 76, 237-252. https://doi. org/10.1016/j.jml.2014.07.004

Kang, C., Fu, Y., Wu, J., Ma, F., Lu, C. \& Guo, T. (2017). Short-term language switching training tunes the neural correlates of cognitive control in bilingual language production. Human Brain Mapping, 38, 5859-5870. https://doi.org/10.1002/hbm.23765

Kaushanskaya, M., Blumenfeld, H. K., \& Marian, V. (2011). The relationship between vocabulary and short-term memory measures in monolingual and bilingual speakers. International Journal of Bilingualism, 15(4), 408-425. https://doi. org/10.1177/1367006911403201

Kiesel, A., Steinhauser, M., Wendt, M., Falkenstein, M., Jost, K., Philipp, A. M., \& Koch, I. (2010). Control and interference in task switching-A review. Psychological Bulletin, 136(5), 849-874. https://doi. org/10.1037/a0019842

Kovács, Á. M., \& Mehler, J. (2009). Cognitive gains in 7-month-old bilingual infants. PNAS Proceedings of the National Academy of Sciences of the United States of America, 106(16), 6556-6560. https://doi. org/10.1073/pnas.0811323106

Liu, C., Yang, C. L., Jiao, L., Schwieter, J. W., Sun, X., \& Wang, R. (2019). Training in language switching facilitates bilinguals' monitoring and inhibitory control. Frontiers in Psychology, 10(1839). https:// doi.org/10.3389/fpsyg.2019.01839

Luo, L., Craik, F. I. M., Moreno, S., \& Bialystok, E. (2013). Bilingualism interacts with domain in a working memory task: Evidence from aging. Psychology and Aging, 28(1), 28-34. https://doi. org/10.1037/a0030875

Marzecova, A., Bukowski, M., Correa, A., Boros, M., Lupianez, J., \& Wodniecka, Z. (2013). Tracing the bilingual advantage in cognitive control: The role of flexibility in temporal preparation and category switching. Journal of Cognitive Psychology, 25(5), 1-19, https://doi.org/10.1080/20445911.2013.809 3.48 .
Miyake, A., Friedman, N. P., Emerson, M. J., Witzki, A. H., Howerter, A., \& Wager, T. D. (2000). The unity and diversity of executive functions and their contributions to complex frontal lobe tasks: A latent variable analysis. Cognitive Psychology, 41, 49100. https://doi.org/10.1006/cogp.1999.0734

Mor, B., Yitzhaki, S., \& Prior, A. (2014). The joint effect of bilingualism and ADHD on executive functions. Journal of Attention Disorders, 19(6), 527-541. https://doi.org/10.1177/1087054714527790

Moradzadeh, L., Blumenthal, G., \& Wisehearta, M. (2014). Musical training, bilingualism, and executive function: A closer look at task switching and dual-task performance. Cognitive Science, 39, 9921020. https://doi.org/10.1111/cogs. 12183

Morton, J. B., \& Harper, S. N. (2007). What did Simon say? Revisiting the bilingual advantage. Developmental Science, 10(6), 719-726. https://doi. org/10.1111/j.1467-7687.2007.00623.x

Nichols, E. S., Wild, C. J., Stojanoski, B., Battista, M. E., \& Owen, A. M. (2020). Bilingualism affords no general cognitive advantages: A population study of executive function in 11,000 people. Psychological Science, 31(5), 548-567. https://doi. org/10.1177/0956797620903113

Nicoladis, E., Hui, D., \& Wiebe, S. A. (2018). Language dominance and cognitive flexibility in French-English bilingual children. Frontiers in Psychology, 9 (1697). https://doi.org/10.3389/fpsyg.2018.01697.

Paap, K. R., \& Greenberg, Z. I. (2013). There is no coherent evidence for a bilingual advantage in executive processing. Cognitive Psychology, 66(2), 232-258. https://doi.org/10.1016/j.cogpsych.2012.12.002

Paap, K. R., Johnson, H. A., \& Sawi, O. (2015). Bilingual advantages in executive functioning either do not exist or are restricted to very specific and undermined circumstances. Cortex, 69, 265-278. https://doi.org/10.1016/j.cortex.2015.04.014

Paap, K. R., Johnson, H. A., \& Sawi, O. (2016). Should the search for bilingual advantages in executive functioning continue? Cortex, 74, 305-314. https:// doi.org/10.1016/j.cortex.2015.09.010

Paap, K. R., Myuz, H. A., Anders, R. T., Bockelman, M. F., Mikulinsky, R., \& Sawi, O. M. (2017). No compelling evidence for a bilingual advantage in switching or that frequent language switching reduces switch cost. Journal of Cognitive Psychology, 29(2), 89-112. https://doi.org/10.1080/2044591 1.2016.1248436

Paap, K. R., \& Sawi, O. (2014). Bilingual advantages in executive functioning: problems in convergent validity, discriminant validity, and the identification of the theoretical constructs. Frontiers 
in Psychology, 5(962). https://doi.org/10.3389/ fpsyg.2014.00962

Papageorgiou, A., Bright, P., Tomas, E. P., \& Filippi, R. (2018). Evidence against a cognitive advantage in the older bilingual population. Quarterly Journal of Experimental Psychology, 1-10. https://doi. org/10.1177/1747021818796475

Prior, A., \& Gollan, T. H. (2011). Good language-switchers are good task-switchers: Evidence from Spanish-English and Mandarin-English bilinguals. Journal of the International Neuropsychological Society, 17,682-691. https://doi.org/10.1017/ S1355617711000580

Prior, A., \& Gollan, T. H. (2013). The elusive link between language control and executive control: A case of limited transfer. Journal of Cognitive Psychology, 25(5), 622-645. https://doi.org/10.1080/2 0445911.2013 .821993

Prior, A., \& Macwhinney, B. (2010). A bilingual advantage in task switching. Bilingualism: Language \& Cognition, 13(2), 253-262. https://doi. org/10.1017/S1366728909990526

Qu, L., Low, J. J. W., Zhang, T., Li, H., \& Zelazo, P. D. (2015). Bilingual advantage in executive control when task demands are considered. Bilingualism: Language and Cognition, 19(2), 1-17. https://doi. org/10.1017/S1366728914000376.

Ramos, S., García, Y. F., Antón, E., Casaponsa, A., \& Duñabeitia, J. A. (2017). Does learning a language in the elderly enhance switching ability? Journal of Neurolinguistics, 43, 39-48. https://doi. org/10.1016/j.jneuroling.2016.09.001

Rodríguez-Pujadas, A., Sanjuán, A., Ventura-Campos, N., Román, P., Martin, C., Barceló, F., et al. (2013). Bilinguals use language-control brain areas more than monolinguals to perform non-linguistic switching tasks. PLoS ONE 8(9): e73028. https:// doi.org/10.1371/journal.pone.0073028

Rubin, O., \& Meiran, N. (2005). On the origins of the task mixing cost in the cuing task-switching paradigm. Journal of Experimental Psychology: Learning, Memory, and Cognition, 31(6), 1477-1491. https://doi.org/10.1037/0278-7393.31.6.1477

Schroeder, S. R., \& Marian, V. (2012). A bilingual advantage for episodic memory in older adults. Journal of Cognitive Psychology, 24(5), 591-601. https:// doi.org/10.1080/20445911.2012.669367

Schweizer, T. A., Ware, J., Fischer, C. E., Craik, F. I. M, \& Bialystok, E. (2012). Bilingualism as a contributor to cognitive reserve: evidence from brain atrophy in Alzheimer's disease. Cortex, 48(8), 991-6. https://doi.org/10.1016/j.cortex.2011.04.009

Shulley, L. J., \& Shake, M. C. (2016). Investigating the relationship between bilingualism, cognitive control, and mind wandering, Journal of Cognitive Psychology, 28(3), 257-274. https://doi.org/10.108 0/20445911.2015.1128438

Sörman, D. E., Hansson, P., \& Ljungberg, J. K. (2019). Different features of bilingualism in relation to executive functioning. Frontiers in Psychology, 10(269). https://doi.org/10.3389/fpsyg.2019.00269

Tao, L., Taft, M., \& Gollan, T. (2015). The bilingual switching advantage: Sometimes related to bilingual proficiency, sometimes not. Journal of the International Neuropsychological Society, 21(7), 531-544. https://doi.org/10.1017/S1355617715000521

Timmer, K., Calabria, M., \& Costa, A. (2019). Non-linguistic effects of language switching training. $\mathrm{Cog}$ nition, 182, 14-24. https://doi.org/10.1016/j.cognition.2018.09.001

Vinerte, S., \& Sabourin, L. (2015). Bilingualism and cognitive control: The ANT in a Canadian context. http://cla-acl.ca/wp-content/uploads/Vinerte_Sabourin-2015.pdf.

von Bastian, C. C., Souza, A. S., \& Miriam, G. (2015). No evidence for bilingual cognitive advantages: A test of four hypotheses. Journal of Experimental Psychology General, 145(2), 246-258. https://doi. org/10.1037/xge0000120

Weissberger, G. H., Gollan, T., Bondi, M. W., Clark, L. R., \& Wierenga, C. E. (2015). Language and task switching in the bilingual brain: Bilinguals are staying, not switching, experts. Neuropsychologia, 66, 193-203. https://doi.org/10.1016/j.neuropsychologia.2014.10.037

Willis, S. L., \& Schaie, K. W. (2009). Cognitive training and plasticity: Theoretical perspective and methodological consequences. Restorative Neurology and Neuroscience, 27(5): 375-389. https://doi. org/10.3233/RNN-2009-0527.

Woumans, E., van Herck, S., \& Struys, E. (2019). Shifting gear in the study of the bilingual advantage: Language switching examined as a possible moderator. Behavioral Sciences, 9(86). https://doi. org/10.3390/bs9080086

Wu, J., Kang, C., Ma, F., Gao, X., \& Guo, T. (2018). The influence of short-term language-switching training on the plasticity of the cognitive control mechanism in bilingual word production. Quarterly Journal of Psychology, 71(10), 2115-2128. https://doi.org/10.1177/1747021817737520

Yang, H., Hartanto, A., \& Yang, S. (2018). Bilingualism confers advantages in task switching: Evidence from the dimensional change card sort task. Bilingualism: Language and Cognition 21(5), 2018, 1091-1109. https://doi.org/10.1017/S136672891700044X 
Zuninia, R. A. L., Morrison, C., Kousaieb, S., \& Taler, V. (2019). Task switching and beilingualism in young and older adults: A behavioral and electrophysiological investigation. Neuropsychologia, 133. https://doi.org/10.1016/j.neuropsychologia.2019.107186 